\title{
Modulations of the executive control network by stimulus onset asynchrony in a Stroop task
}

\author{
Emily $L$ Coderre ${ }^{1,2^{*}}$ and Walter J B van Heuven ${ }^{1}$
}

\begin{abstract}
Background: Manipulating task difficulty is a useful way of elucidating the functional recruitment of the brain's executive control network. In a Stroop task, pre-exposing the irrelevant word using varying stimulus onset asynchronies ('negative' SOAs) modulates the amount of behavioural interference and facilitation, suggesting disparate mechanisms of cognitive processing in each SOA. The current study employed a Stroop task with three SOAs (-400, $-200,0$ ms), using functional magnetic resonance imaging to investigate for the first time the neural effects of SOA manipulation. Of specific interest were 1) how SOA affects the neural representation of interference and facilitation; 2) response priming effects in negative SOAs; and 3) attentional effects of blocked SOA presentation.

Results: The results revealed three regions of the executive control network that were sensitive to SOA during Stroop interference; the 0 ms SOA elicited the greatest activation of these areas but experienced relatively smaller behavioural interference, suggesting that the enhanced recruitment led to more efficient conflict processing. Response priming effects were localized to the right inferior frontal gyrus, which is consistent with the idea that this region performed response inhibition in incongruent conditions to overcome the incorrectly-primed response, as well as more general action updating and response preparation. Finally, the right superior parietal lobe was sensitive to blocked SOA presentation and was most active for the 0 ms SOA, suggesting that this region is involved in attentional control.
\end{abstract}

Conclusions: SOA exerted both trial-specific and block-wide effects on executive processing, providing a unique paradigm for functional investigations of the cognitive control network.

Keywords: fMRI, Stroop task, Stimulus onset asynchrony, Cognitive control

\section{Background}

The term 'cognitive control' refers to a broad array of cognitive situations in which distracting information must be ignored, a habitual response must be overcome, or one must switch between varying mental sets. In the cognitive psychology literature, cognitive control is labeled more formally as 'executive function', a category which spans a number of cognitive functions such as working memory, response selection and/or suppression, and conflict detection and resolution. A vast amount of literature has been dedicated to understanding the cognitive and neural mechanisms of these various aspects of

\footnotetext{
* Correspondence: ecoderr1@jhmi.edu

'School of Psychology, University of Nottingham, University Park, Nottingham NG7 2RD, UK

${ }^{2}$ Department of Neurology, Johns Hopkins University School of Medicine, 1629 Thames St. Suite 350, Baltimore, MD 21231, USA
}

executive control, and with the emergence of neuroimaging technologies such as positron emission tomography (PET), magnetoencephalography (MEG) and functional magnetic resonance imaging (fMRI), this literature has grown enormously.

Previous work using fMRI has identified an extensive network of executive control consisting of regions across the prefrontal and parietal cortices that participate in a range of cognitive functions. For example, the rostral cingulate zone (RCZ; located along the borders of Brodmann areas (BAs) 6, 8, 32 and 24 in the medial frontal cortex) is thought to be involved in performance monitoring [1]. A subset of this region, the anterior cingulate cortex (ACC: Brodmann areas (BAs) 24/32) is clearly involved in executive control but is highly debated regarding its precise function, being implicated in processes such as conflict monitoring [2-4], top-down

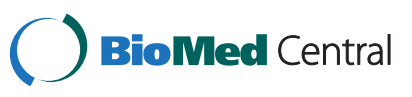


regulation of conflict [5], and anticipatory adjustments in control [6], to name a few (see $[1,7,8]$ for reviews). Other frontal areas such as the middle and inferior frontal gyri, including the dorsolateral prefrontal cortex (DLPFC; BAs 9/46) are involved in conflict processing and regulation of executive control [2-4,7]. The left inferior frontal gyrus (LIFG) is believed to implement cognitive control via suppression of irrelevant semantic information [9-12], while the right inferior frontal gyrus (RIFG) is involved in inhibitory control, specifically response inhibition [13-16]. The inferior (BAs 39/40) and superior (BA 7) parietal lobes are involved in top-down visuospatial control of attention towards the task-relevant target or attribute [17-20]. Other areas of the prefrontal cortex such as the premotor (BA 6) and frontopolar (BA 10) cortices are also involved, as are subcortical structures such as the thalamus and caudate (e.g. $[1,21,22]$; see $[23,24]$ for meta-analyses).

Although a number of alternative theories exist regarding the precise function of these structures, especially the ACC (e.g. [6,7,25]), DLPFC (e.g. [26]), and RIFG (e.g. [15,27]), these areas are reliably activated for a spectrum of executive control functions, including working memory, cognitive flexibility, vigilance or sustained attention, and - importantly for this study - inhibition of prepotent behaviours and the management of cognitive conflict [23]. The activation and recruitment of this executive control system is also affected by various task parameters, such as the context, magnitude, and nature of cognitive conflict (e.g. [19,28-30]). This malleability of the executive control network highlights its dynamic, moment-to-moment recruitment of different conflict processing strategies. The current study specifically explored how this network is modulated by SOA manipulation in the Stroop task.

This paradigm presents a colour word printed in coloured ink, and asks subjects to ignore the word and respond to its ink colour [31]. Interference arises in incongruent conditions (e.g. blue printed in red ink, correct response "red") due to the conflicting semantic and response information, and longer reaction times (RTs) arise because the automatic process of word reading must be overcome in order to name the colour. The Stroop task recruits the canonical executive control network, generating stronger activation for incongruent trials (e.g. [24,32-35]). Many variations of the Stroop task have been employed with fMRI to investigate the precise function of executive control structures (e.g. [19,36,37]).

One notable variation is stimulus onset asynchrony (SOA) manipulation, which spatially separates the colour and word stimuli (e.g. a coloured rectangle surrounding the word) and presents them at different times in order to gain temporal information on colour and word interference. A 'negative SOA' presents the irrelevant stimulus (e.g. the word) before the relevant target stimulus (the colour) at a specific interval. For example, a negative $200 \mathrm{~ms}$ SOA ('-200 ms SOA') pre-exposes the word for $200 \mathrm{~ms}$ before the colour appears. A ' $0 \mathrm{~ms}$ SOA' presents the word and colour simultaneously, as in a traditional Stroop task. Typically, the strongest interference effects (incongruent minus control) occur at $-200 \mathrm{~ms}$ to $0 \mathrm{~ms}$ SOAs [38-41]. Interference is decreased, but remains significant, at negative SOAs out to $-400 \mathrm{~ms}$. Facilitation effects (control minus congruent) are generally found for negative SOAs and not for positive SOAs beyond +200 ms [38,39,41,42], but facilitation typically does not differ across negative SOAs $[38,41,43,44]$. At the $0 \mathrm{~ms}$ SOA, some researchers report significant facilitation effects [40] and some do not $[38,39,41,42]$.

The Stroop task is traditionally administered with a verbal response, in which participants name the colour of the ink aloud. A manual response modality, which uses a button-press instead of a vocal response, results in decreased (but still significant) interference effects [45], as well as faster reaction times overall [36,45-47]. SOA has been found to elicit different patterns of interference effects depending on the response modality: vocal responses elicit the maximum amount of interference at a $0 \mathrm{~ms}$ SOA (e.g. $[38,41])$, whereas manual responses shift the peak of interference to the $-200 \mathrm{~ms}$ SOA due to the faster manual response time $[39,40]$. In terms of facilitation effects, manual and vocal responses appear to have similar effects on facilitation magnitude across SOAs, with significant facilitation effects for negative SOAs and no facilitation for positive SOAs [38-42].

SOA variation has proven to be a useful manipulation of the Stroop task because it provides temporal information about the speed of processing of the two conflicting stimulus dimensions. To investigate these temporal effects further, recent studies have employed Stroop SOA manipulation with electroencephalography (EEG), to investigate how pre- or post-exposure of the word affects conflict-related ERP components $[40,42,48]$. These studies have demonstrated that the onset and duration of the $\mathrm{N}_{\text {inc }}$ or N450 (an ERP component thought to be indicative of conflict detection) is modulated by SOA, and that this component is sensitive to conflict across a variety of task designs and conflict demands. However, the current study is the first to explore the neural effects of Stroop SOA manipulation (using $-400 \mathrm{~ms},-200 \mathrm{~ms}$, and $0 \mathrm{~ms}$ SOAs) on the activation and recruitment of the executive control network using fMRI. Based on prior research, this study addressed three specific cognitive aspects of SOA manipulation.

\section{SOA effects on neural conflict and facilitation}

First, the current study explored how the executive control network in the brain is modulated by conflict and 
facilitation effects in each SOA. Behaviourally, each SOA generates different magnitudes of interference and facilitation, with maximal interference at simultaneous presentation or short word pre-exposure (i.e. $0 \mathrm{~ms}$ or $-200 \mathrm{~ms}$ ) and significant facilitation at negative SOAs [38-40,42]. Furthermore, the $\mathrm{N}_{\text {inc }}$ ERP component is sensitive to conflict across a variety of task designs and conflict demands $[40,42,48]$. This modulation of conflict and facilitation effects suggests the participation of different cognitive control mechanisms for each SOA. The primary aim of the current study was therefore to explore how these 'trial-specific' effects of SOA affected the activation of the executive control network.

Overall, typical executive control areas of the prefrontal cortex were expected to be elicited by incongruency in the 0 ms SOA (as this was analogous to a traditional Stroop task), such as the RCZ, left middle/medial frontal gyrus (LMFG), and LIFG (e.g. [1,3,12,21-23]), as well as parietal regions such as the left angular gyrus [12,32,49,50] and the inferior/superior parietal lobe [17-20]. Activation in these areas was also expected for the $-400 \mathrm{~ms}$ and $-200 \mathrm{~ms}$ SOAs, although with potentially different extents and/or strengths of activation compared to the $0 \mathrm{~ms}$ SOA. For example, the executive control network has demonstrated stronger activation in the presence of more conflict (e.g. [29]), so increased behavioural interference in the $-200 \mathrm{~ms}$ SOA may be reflected in stronger neural recruitment of these areas.

\section{Response priming effects in negative SOAs}

The second topic addressed in the current study regarded the effects of response priming in negative SOAs. Appelbaum et al. [40] have proposed that in negative SOAs, word pre-exposure creates a priming effect by pre-activating response selection. In congruent conditions this accelerates processing time because the subsequentlypresented colour matches the pre-activated information, leading to larger behavioural facilitation effects. In contrast, incongruent conditions require more conflict control to overcome or inhibit the primed response, increasing behavioural RTs and interference effects. Increased interference and facilitation effects have been previously documented at the $-200 \mathrm{~ms} \mathrm{SOA}$, in line with this proposal of response priming effects $[39,40]$. The current study sought to establish the neural correlates of response priming effects in negative SOAs.

Response priming effects were expected in executive control areas linked to response preparation, such as the DLPFC [51] or supplementary and cingulate motor areas [52]. This activation was predicted to be stronger in the $-200 \mathrm{~ms} \mathrm{SOA}$, and potentially also the $-400 \mathrm{~ms}$ $\mathrm{SOA}$, compared to the $0 \mathrm{~ms}$ SOA. Furthermore, if the increased behavioural interference in the $-200 \mathrm{~ms}$ SOA arises from the need to overcome the primed response in incongruent conditions, evidence of response priming may also be observed in areas linked to response inhibition, such as the RIFG [13-16].

\section{Attentional effects of blocked SOA presentation}

Finally, the third aspect of SOA manipulation investigated in this study concerned the effects of blocked SOA presentation. Appelbaum et al. [48] have recently observed different patterns of interference for blocked and mixed SOA presentation. Specifically, temporallypredictable SOAs, as in blocked presentations, may lead to a strategic orientation of attention which could modulate the amount of conflict experienced. In their EEG data, Appelbaum et al. [48] demonstrated that although the $\mathrm{N}_{\text {inc }}$ tracked the onset of conflict across SOA manipulation, a larger $\mathrm{N}_{\text {inc }}$ component occurred in the $0 \mathrm{~ms}$ SOA when SOAs were blocked, whereas when SOAs were randomized a larger $\mathrm{N}_{\text {inc }}$ occurred in the $-200 \mathrm{~ms}$ SOA. In blocks of negative SOAs, the pre-exposed word may have acted as an alerting cue for the upcoming target information, prompting participants to use this cue to strategically orient their attention towards the target stimulus. In contrast, in the $0 \mathrm{~ms}$ SOA this strategy could not be used, leading to larger interference effects. Therefore Appelbaum et al. [48] proposed that the temporal predictability of blocked SOAs encourages an attentional orientation strategy. On the other hand, Roelofs [41] has also investigated this issue of blocked versus mixed SOA presentation using a behavioural paradigm and reported that, although overall RTs were affected, no difference in interference patterns occurred between SOA presentation methods. This argues against such a temporal predictability effect, but it may be that the electrophysiological technique used in Appelbaum et al. [48] was more sensitive to strategic attentional effects. The current study therefore also investigated global attentional effects of blocked SOA presentation.

If blocked SOA presentation engages strategic attentional processes, such block-wide SOA effects should be observable in all congruency conditions. The current study investigated these global (i.e. block-wide and conflict-independent) effects of strategic attentional control by first collapsing over congruencies and comparing SOAs, as well as comparing congruency conditions across SOAs (e.g. $-400 \mathrm{~ms}$ control vs. $0 \mathrm{~ms}$ control). Global SOA effects on attentional orientation were expected in areas involved in top-down attentional control such as the right parietal lobe, specifically the angular gyrus (BA 40) and superior parietal lobe (BA 7; [17-20]). Specifically, if subjects use the pre-exposed word in negative SOAs as a temporal cue, activation in these attentional control areas should be enhanced in the $-200 \mathrm{~ms}$ and $-400 \mathrm{~ms}$ SOAs compared to the $0 \mathrm{~ms}$ SOA. 
In summary, the current study employed a Stroop task with negative SOA modulation in fMRI to explore how SOA affects the recruitment and performance of the executive control network. Of specific interest were 1) the effects of SOA on Stroop, interference, and facilitation effects in the brain; 2) response priming effects in negative SOAs; and 3) global effects of blocked SOA presentation on attention.

\section{Methods}

\section{Participants}

Fourteen right-handed participants who had no history of neurological disorder, no colour-blindness, and normal vision, were recruited from the University of Nottingham in the UK. The participants were 10 males and 4 females with a mean age of 25 years $(\mathrm{SD}=4.2)$. This study was approved by the University of Nottingham Medical Ethics Committee. All subjects gave informed written consent according to the ethics guidelines of the University of Nottingham Medical Ethics Committee and in accordance with the Helsinki Declaration. Participants were offered an inconvenience allowance for their participation.

\section{Design and materials}

Three SOAs were used: $-400 \mathrm{~ms},-200 \mathrm{~ms}$, and $0 \mathrm{~ms}$. Word stimuli consisted of the words 'red', 'green', and 'blue' in lowercase letters printed in white ink on a black background. A non-colour, non-word stimulus that matched the visual input of the words ('\%\%\%\%) was included as a control stimulus, also printed in white ink on a black background. Colour stimuli for both tasks were red, green and blue rectangles surrounding the word stimuli. Participants were asked to respond to the colour of the rectangle by pressing a button on an MRIcompatible button box (right index finger for red, right middle finger for green, right ring finger for blue).

\section{Procedure}

The scanning session lasted approximately 1 hour including set-up, structural image acquisition, and experimental testing. Stimuli were presented using E-Prime. In addition to the three SOAs of the Stroop task, participants also performed a run of a flanker task (data not reported here). ${ }^{a}$ Task order (Stroop or flanker) was counterbalanced between participants. Each run was approximately 7 minutes long. SOAs were blocked and their order of presentation was counterbalanced. Within each task block, conditions were presented in an eventrelated fashion.

Each SOA consisted of 120 trials (30 each of congruent, control, incongruent and null events). In the $-400 \mathrm{~ms}$ SOA, the word appeared on the screen alone for $400 \mathrm{~ms}$ before being surrounded by the coloured rectangle (see Figure 1). In the $-200 \mathrm{~ms}$ SOA, the word appeared for
$200 \mathrm{~ms}$ before being surrounded by the colour. In the $0 \mathrm{~ms}$ SOA, both stimuli appeared simultaneously. Once both word and colour stimuli had appeared, both remained on the screen for $1000 \mathrm{~ms}$. In null-event trials, a non-bold fixation cross remained on the screen for 750 ms. Each trial was followed by an ISI fixation screen with a non-bold fixation cross, varying from 1500$2900 \mathrm{~ms}$ in 200-ms intervals (average $2200 \mathrm{~ms}$ ). The trial order was pseudo-randomly presented such that each trial type (congruent, control, incongruent) was followed equally often by a null event trial, and there were no occurrences of the same trial type occurring twice in a row throughout a block.

\section{fMRI scan procedure and pre-processing}

Structural and functional MRI scans were acquired using a Philips Achieva 3.0 Tesla scanner at the Sir Peter Mansfield Magnetic Resonance Centre at the University of Nottingham. A sagittal T1-weighted volumetric sequence (TR $7600 \mathrm{~ms}$, TE $2.3 \mathrm{~ms}$, flip angle 8 degrees, NSA 1.0, FOV $256 \mathrm{~mm}, 256 \times 256$ matrix, $1.0 \mathrm{~mm}$ slice thickness, no gap, 184 slices) was acquired as a structural reference scan. fMRI was collected using gradientecho EPI BOLD (echoplanar blood oxygenation level dependent) pulse sequences (TR $2500 \mathrm{~ms}$, TE $40 \mathrm{~ms}$, flip angle 90 degrees, $1 \mathrm{NSA}$, SENSE factor 2.3, resolution $3 \times 3 \times 3 \mathrm{~mm}$, 38 slices of $3 \mathrm{~mm}$ thickness, no gap, FOV $240 \mathrm{~mm}$, matrix size $80 \times 80$ ).

All pre-processing and data analyses were performed using SPM8 (Wellcome Trust Centre for Neuroimaging, "Statistical Parametrical Mapping, SPM8", http://www. fil.ion.ucl.ac.uk/spm/). For each subject, functional images were spatially realigned to the first volume of the first run to account for motion during the scan. The anatomical scan was then co-registered to a mean EPI image of the realigned functional scans. The original anatomical scan was segmented using DARTEL [53] into grey matter (GM), white matter (WM) and cerebrospinal fluid (CSF) in order to create a template of transformation parameters for normalizing the anatomical image to an MNI template brain. Functional and structural images were then normalized using these parameters. The normalized functional images were spatially smoothed using an $8 \mathrm{~mm}$ FWHM isotropic Gaussian kernel.

\section{fMRI analyses}

Vectors of stimuli onsets were created for each trial type. For the analyses addressing the question of SOA effects on neural interference and facilitation, onsets were defined as the onset time of the colour stimulus, which was the second stimulus presented in the negative SOAs and therefore corresponded to the onset of conflict. For the analyses investigating global SOA effects (response priming effects in negative SOAs and effects of blocked 


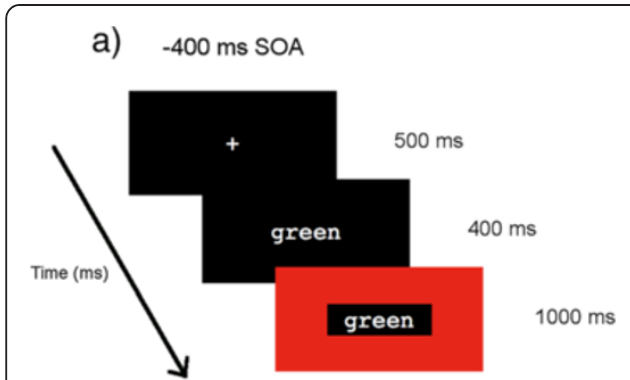

b)

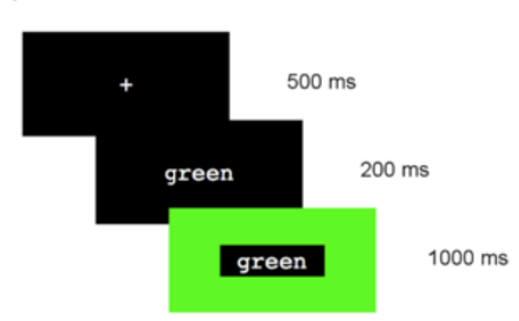

c) $0 \mathrm{~ms} \mathrm{SOA}$

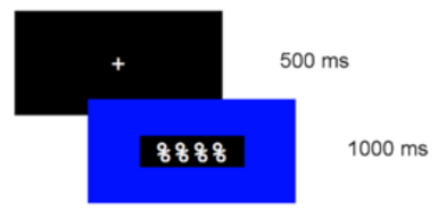

Figure 1 Illustration of paradigm. Examples of a) a -400 ms SOA incongruent condition; b) a -200 ms SOA congruent condition; and c) a 0 ms SOA control condition. Duration (ms) of each stimulus is indicated to the right.

SOAs on strategic attentional orientation), onsets were defined as the onset time of the first stimulus presented (i.e. in negative Stroop SOAs, onset of the word stimulus). Behavioural errors and outliers were included as additional conditions in the model specification. Six realignment parameters from the realignment step of preprocessing were also included as covariates. The stimuli onset vectors were convolved using a canonical HRF plus the temporal derivative. Statistical analyses based on general linear modeling (GLM) were then performed by multiple linear regression of the signal time course in each voxel. The three Stroop runs $(0 \mathrm{~ms},-200 \mathrm{~ms}$, and $-400 \mathrm{~ms}$ SOAs) were modeled together in the same design matrix. Three directional contrasts of interest were performed for each SOA (Stroop: incongruent > congruent; interference: incongruent > control; facilitation: control > congruent). Both the nonderivative and the temporal derivative were included when defining the contrasts, in order to avoid amplitude bias and to capture the temporal shift in the hemodynamic response function as a result of negative SOA presentation [54]. Percent signal change was calculated using Marsbar [55], and significant regions were labeled using the WFU PickAtlas package [56] and confirmed using the Talairach Client [57,58]. In all tables, regions and Brodmann areas (BA) for the entire cluster are listed, while Z-score and MNI coordinates are reported for the peak of the cluster. In identifying significant areas of activation in all analyses, an uncorrected $p$-value of $p<0.001$ for the height (intensity) threshold of each activated voxel was used, with an extent threshold (cluster size) of 30 voxels.

\section{Results}

\section{Behavioural data}

Incorrect responses (5.9\%) and outliers (RTs of less than 250 or greater than $2000 \mathrm{~ms}$; 0.3\%) were removed before analyses. Because error rates were very low, no error analyses were performed. The mean RTs and magnitudes of Stroop (incongruent minus congruent RTs), interference (incongruent minus control ('\%\%\%\%)), and facilitation (control minus congruent) effects are shown in
Figure 2. A 3 (congruency) $\times 3(\mathrm{SOA})$ ANOVA showed a main effect of congruency $(F(2,26)=20.27, p<0.0001)$ but not of SOA $(F(2,26)=1.75, p=0.19)$, and an interaction of SOA and congruency $(F(4,52)=4.86, p<0.01)$. Significant Stroop effects occurred in the $-400 \mathrm{~ms}(t(13)=2.17, p<$ $0.05),-200 \mathrm{~ms}(t(13)=8.06, p<0.0001)$ and $0 \mathrm{~ms}$ SOAs $(t(13)=2.76, p<0.05)$. Significant interference occurred in the $-200 \mathrm{~ms}(t(13)=4.60, p<0.001)$ and $0 \mathrm{~ms}$ SOAs $(t(13)=2.56, p<0.05)$, and significant facilitation in the $-400 \mathrm{~ms}(t(13)=3.42, p<0.01)$ and $-200 \mathrm{~ms}$ SOAs $(t(13)=2.91, p<0.05)$. The $-200 \mathrm{~ms}$ SOA generated the largest Stroop (108 ms, $S E=13 \mathrm{~ms}$; Figure 2b) and interference (68 ms, $S E=15$; Figure 2c) effects. Similar facilitation effects occurred at the $-400 \mathrm{~ms}$ SOA (45 $\mathrm{ms}, S E=13 \mathrm{~ms}$ ) and the $-200 \mathrm{~ms}$ SOA (39 ms, $S E=14 \mathrm{~ms}$ ), whereas facilitation was absent in the $0 \mathrm{~ms}$ SOA $(0.4 \mathrm{~ms}, S E=10 \mathrm{~ms}$; Figure 2d).

\section{fMRI data}

\section{Trial-specific effects of SOA}

As outlined in the Introduction, this study first investigated how SOA affected the neural representations of conflict and facilitation effects. Before comparing SOAs to address this question, the contrasts of interest (Stroop, interference, and facilitation) were investigated for each SOA individually using one-sample $t$-tests (Table 1 ).

In the $0 \mathrm{~ms} \mathrm{SOA}$ (shown in red in Figures 3, 4 and 5), the Stroop contrast revealed activation in cognitive control areas in the prefrontal and parietal cortices such as the LMFG (BAs 6/10), bilateral superior parietal lobes/ angular gyri (BAs 7/40), LIFG (BA 46), posterior cingulate (BA 23) and ACC/RCZ (BAs 6/8/32), as well as subcortical activation in the left thalamus and right caudate nucleus (Table 1 and Figure 3). Similar areas were activated in the interference contrast (Figure 4): the bilateral superior parietal lobes/angular gyri (BA 40), LMFG (BAs 6/9), LIFG (BA 46), left ACC/RCZ (BA 8/32), and right caudate. The facilitation contrast showed no significant areas of activation for the $0 \mathrm{~ms}$ SOA (Figure 5).

In the $-200 \mathrm{~ms}$ SOA (shown in green in Figures 3, 4 and 5), the Stroop contrast revealed activation in similar 


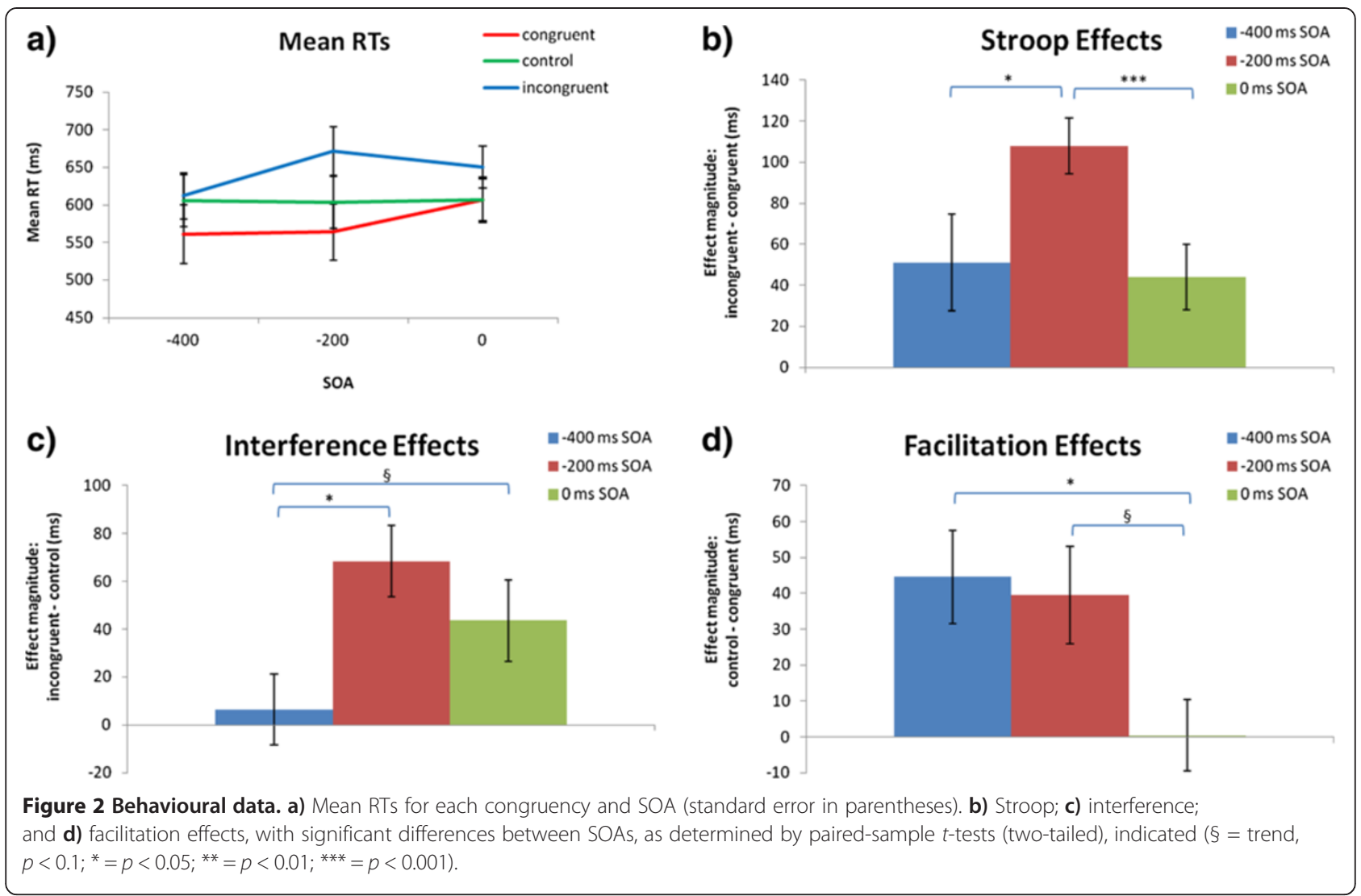

cognitive control areas as the $0 \mathrm{~ms}$ SOA: the bilateral insula/IFG (BAs 13/47), LIFG/LMFG (BAs 44/6/9), right MFG (BA 6), ACC/RCZ (BAs 6/32), left superior parietal lobe/angular gyrus (BAs 7/40), and the right middle temporal gyrus (BA 37; Table 1 and Figure 3). In the interference contrast (Figure 4), significant clusters of activation were observed in the bilateral IFG/MFG (BAs 9/44/45/46/47), and right superior parietal lobule (BA7). The facilitation contrast showed significant activation in the left and right postcentral gyrus (BAs 2/40), the left precentral gyrus (BAs 6/4), and the right posterior cingulate (BA 30; Figure 5).

In the $-400 \mathrm{~ms}$ SOA (shown in blue in Figures 3, 4 and 5), the Stroop contrast revealed a cluster in the left middle/superior frontal gyrus (BA 6; Table 1, Figure 3). The interference contrast (Figure 4) revealed significant activation in the bilateral thalamus, right IFG (BA 47), and right superior temporal gyrus (BA 22). The facilitation contrast showed no significant activation (Figure 5).

\section{SOA modulation of neural interference and facilitation effects}

To investigate trial-specific effects of SOA on conflict and facilitation, three second-level ANOVAs were performed (for the Stroop, interference, and facilitation effects, respectively) by entering the first-level effect contrasts for each SOA into a 1-way ANOVA with three levels (SOA; Table 2).

The Stroop ANOVA revealed no significant clusters of activation. The interference effects elicited a main effect of SOA in three areas of the control network (Figure 6a): the RCZ (BA 8), right superior frontal gyrus (BA 9), LMFG (BA 6), and right superior parietal lobule (BA 7), as well as a cluster in the right paracentral lobule (BA 5/3). To further investigate how SOA modulated interference effects in these regions, the percent signal change for each condition was extracted from these three ROIs. The percent signal change interference effects (i.e. incongruent signal change minus control signal change; Figure $6 \mathrm{~b}$ ) demonstrated the largest neural interference effects in these areas in the $0 \mathrm{~ms} \mathrm{SOA}$. Finally, the facilitation effects elicited a main effect of SOA in the right inferior parietal lobe (BAs 40/2; Table 2 and Figure $6 \mathrm{c}$ ). To investigate the direction of these effects the percent signal change was extracted for this cluster (Figure 6d). Percent signal change demonstrated that in the negative SOAs the control stimuli had greater percent signal change than congruent $(-200 \mathrm{~ms}$ SOA: control $=$ 0.20 , congruent $=0.14 ;-400 \mathrm{~ms}$ SOA: control $=0.14$, congruent $=0.09$ ), whereas in the $0 \mathrm{~ms} \mathrm{SOA}$ the congruent and control stimuli elicited similar levels of percent signal change $(0 \mathrm{~ms}$ SOA control $=0.01$, congruent $=0.02)$. 
Table 1 Main effects of interest (clusters > 30 voxels) for each SOA

\begin{tabular}{|c|c|c|c|c|c|c|c|c|}
\hline \multirow[t]{2}{*}{ SOA } & \multirow[t]{2}{*}{ Contrast } & \multirow[t]{2}{*}{ Region } & \multirow[t]{2}{*}{$\mathrm{BA}(\mathrm{s})$} & \multicolumn{3}{|c|}{$\begin{array}{c}\text { MNI } \\
\text { coordinates } \\
\end{array}$} & \multirow{2}{*}{$\begin{array}{l}\text { Cluster } \\
\text { size }\end{array}$} & \multirow{2}{*}{$\begin{array}{c}\text { Peak } \\
\text { Z-score }\end{array}$} \\
\hline & & & & $\mathbf{x}$ & y & z & & \\
\hline \multirow[t]{29}{*}{$0 \mathrm{~ms} \mathrm{SOA}$} & \multirow[t]{15}{*}{ Stroop effect } & L precentral gyrus/postcentral gyrus & $6 / 44$ & -56 & -4 & 44 & 613 & 4.70 \\
\hline & & Medial frontal gyrus/ACC/RCZ & $8 / 6 / 32$ & 4 & 26 & 46 & 209 & 3.88 \\
\hline & & L inferior/superior parietal lobule/angular gyrus & $40 / 7$ & -34 & -50 & 46 & 185 & 4.07 \\
\hline & & L middle temporal gyrus/angular gyrus/superior parietal lobule & $39 / 7 / 19$ & -36 & -72 & 26 & 171 & 4.08 \\
\hline & & $\mathrm{L}$ middle/inferior frontal gyrus & $46 / 10$ & -40 & 38 & 22 & 159 & 4.90 \\
\hline & & L superior temporal gyrus/supramarginal gyrus & $22 / 40$ & -58 & -36 & 22 & 117 & 4.40 \\
\hline & & R precuneus/superior parietal lobule & 7 & 12 & -70 & 44 & 90 & 3.85 \\
\hline & & R superior temporal gyrus & $41 / 13$ & 48 & -38 & 14 & 60 & 4.03 \\
\hline & & L paracentral lobe/precentral gyrus/medial frontal gyrus & 6 & -6 & -30 & 60 & 54 & 3.67 \\
\hline & & R inferior parietal lobe/superior temporal gyrus/supramarginal gyrus & 40 & 66 & -40 & 22 & 49 & 4.24 \\
\hline & & Posterior cingulate & $29 / 23$ & -2 & -40 & 18 & 48 & 3.81 \\
\hline & & R inferior temporal gyrus/lateral occipitotemporal gyrus & 20/37 & 50 & -54 & -14 & 47 & 3.62 \\
\hline & & R inferior/superior parietal lobule/angular gyrus & 40 & 32 & -54 & 38 & 45 & 3.59 \\
\hline & & L medial dorsal nucleus/thalamus & - & -10 & -20 & 12 & 41 & 3.68 \\
\hline & & R putamen/caudate nucleus & - & 16 & 2 & 10 & 30 & 3.73 \\
\hline & \multirow[t]{13}{*}{ Interference effect } & L superior parietal lobule/angular gyrus & $7 / 40$ & -12 & -60 & 54 & 1082 & 4.75 \\
\hline & & $L$ middle frontal gyrus & $8 / 9$ & -50 & 18 & 38 & 267 & 4.00 \\
\hline & & $\mathrm{L}$ inferior/middle frontal gyrus & 46 & -50 & 30 & 16 & 198 & 4.12 \\
\hline & & L medial frontal gyrus/ACC/RCZ & $8 / 32$ & -4 & 28 & 40 & 173 & 4.13 \\
\hline & & R paracentral lobe/precentral/postcentral gyrus & $5 / 6$ & 12 & -38 & 52 & 100 & 3.76 \\
\hline & & L cingulate/medial frontal gyrus & $31 / 6$ & -16 & -20 & 44 & 83 & 3.71 \\
\hline & & R precuneus/superior parietal lobule & 7 & 18 & -74 & 46 & 81 & 3.67 \\
\hline & & $\mathrm{L}$ middle frontal gyrus & 6 & -40 & 2 & 52 & 67 & 4.11 \\
\hline & & L fusiform gyrus/lateral occipitotemporal gyrus & $37 / 19$ & -44 & -50 & -14 & 66 & 3.79 \\
\hline & & L superior/middle temporal gyrus & 39 & -56 & -62 & 18 & 44 & 3.99 \\
\hline & & R caudate nucleus & - & 14 & 6 & 18 & 43 & 4.11 \\
\hline & & R supramarginal gyrus/angular gyrus & 40 & 58 & -46 & 24 & 43 & 3.74 \\
\hline & & $\mathrm{L}$ middle temporal gyrus/middle occipital gyrus & 39 & -52 & -72 & 22 & 36 & 4.55 \\
\hline & Facilitation effect & No voxels surviving thresholding & -- & -- & -- & -- & -- & -- \\
\hline \multirow[t]{13}{*}{$-200 \mathrm{~ms}$ SOA } & \multirow[t]{10}{*}{ Stroop effect } & R inferior frontal gyrus/insula & $45 / 13 / 47$ & 34 & 28 & 6 & 285 & 4.87 \\
\hline & & L precentral gyrus/inferior frontal gyrus & $6 / 44 / 9$ & -52 & 8 & 30 & 211 & 3.90 \\
\hline & & L superior/medial frontal gyrus /ACC/RCZ & $8 / 32 / 6$ & -8 & 10 & 48 & 80 & 4.27 \\
\hline & & $\mathrm{L}$ inferior frontal gyrus/insula & $45 / 13 / 47$ & -30 & 28 & 4 & 74 & 3.68 \\
\hline & & $\mathrm{R}$ anterior/middle cingulate & 32 & 8 & 38 & 22 & 63 & 3.84 \\
\hline & & $\mathrm{R}$ middle temporal gyrus & 37 & 54 & -54 & 0 & 55 & 3.87 \\
\hline & & $\mathrm{R}$ medial frontal gyrus/anterior cingulate & 10 & 8 & 56 & 8 & 55 & 3.61 \\
\hline & & R superior frontal gyrus/SMA & 6 & 8 & 12 & 50 & 37 & 3.85 \\
\hline & & L superior/inferior parietal lobe & 7 & -24 & -56 & 42 & 36 & 3.67 \\
\hline & & $\mathrm{L}$ inferior parietal lobe & $40 / 2$ & -44 & -38 & 46 & 35 & 3.89 \\
\hline & \multirow[t]{3}{*}{ Interference effect } & $\mathrm{L}$ inferior/middle frontal gyrus & $9 / 46$ & -48 & 16 & 24 & 148 & 3.91 \\
\hline & & R precuneus/superior parietal lobule & 7 & 6 & -66 & 42 & 102 & 3.87 \\
\hline & & R precentral gyrus/inferior frontal gyrus & $44 / 47$ & 50 & 16 & -8 & 70 & 4.04 \\
\hline
\end{tabular}


Table 1 Main effects of interest (clusters > $\mathbf{3 0}$ voxels) for each SOA (Continued)

\begin{tabular}{|c|c|c|c|c|c|c|c|c|}
\hline & & R superior parietal lobe/angular gyrus & 7 & 34 & -56 & 48 & 37 & 3.76 \\
\hline & & $\mathrm{R}$ middle/inferior frontal gyrus & $9 / 45$ & 50 & 20 & 28 & 35 & 3.62 \\
\hline & Facilitation effect & No voxels surviving thresholding & -- & -- & -- & -- & -- & -- \\
\hline \multirow[t]{6}{*}{$-400 \mathrm{~ms}$ SOA } & Stroop effect & L middle/superior frontal gyrus & 6 & -20 & -8 & 62 & 61 & 4.27 \\
\hline & Interference effect & $\mathrm{R}$ thalamus & - & 14 & -22 & 10 & 236 & 4.67 \\
\hline & & $\mathrm{R}$ inferior frontal gyrus & $44 / 45 / 47$ & 50 & 14 & -6 & 133 & 4.48 \\
\hline & & $\mathrm{L}$ thalamus & - & -10 & -22 & 4 & 79 & 4.21 \\
\hline & & $\mathrm{R}$ middle/superior temporal gyrus & 22 & 58 & -32 & 2 & 77 & 4.79 \\
\hline & Facilitation effect & No voxels surviving thresholding & -- & -- & -- & -- & -- & -- \\
\hline
\end{tabular}

Legend: Regions and Brodmann areas (BA) for the entire cluster are listed. Cluster size reported is number of voxels. Z-score and MNI coordinates are taken from the peak of the cluster.

\section{Global (block-wide) effects of SOA}

As discussed in the Introduction, SOA was predicted to create global (i.e. block-wide or conflict-independent) effects of response priming in negative SOAs [40] and of attentional control due to blocked SOA presentation [48]. These effects of SOA were expected when evaluating block-wide SOA effects (collapsing over congruencies), as well as when directly comparing congruencies between SOAs. For example, block-wide attentional orientation should be present in all congruencies, leading to differences even when comparing control conditions between SOAs.
To investigate block-wide SOA effects, each SOA was first collapsed over congruencies (contrasted with nullevent trials: (incongruent, control, congruent) > null) and entered into a 1-way ANOVA with three levels (SOA). Two main regions emerged that were sensitive to global SOA effects: the RIFG (BAs 45/47; part of a RIFG cluster also extended into the ACC/BA 32) and the right superior parietal lobe (BA 7; see Figure 7 and Table 3). The percent signal change for each SOA was also extracted from these two regions, which revealed larger overall effects for the $0 \mathrm{~ms}$ SOA (when collapsed across congruencies: Figure 7b). A block effect of SOA was

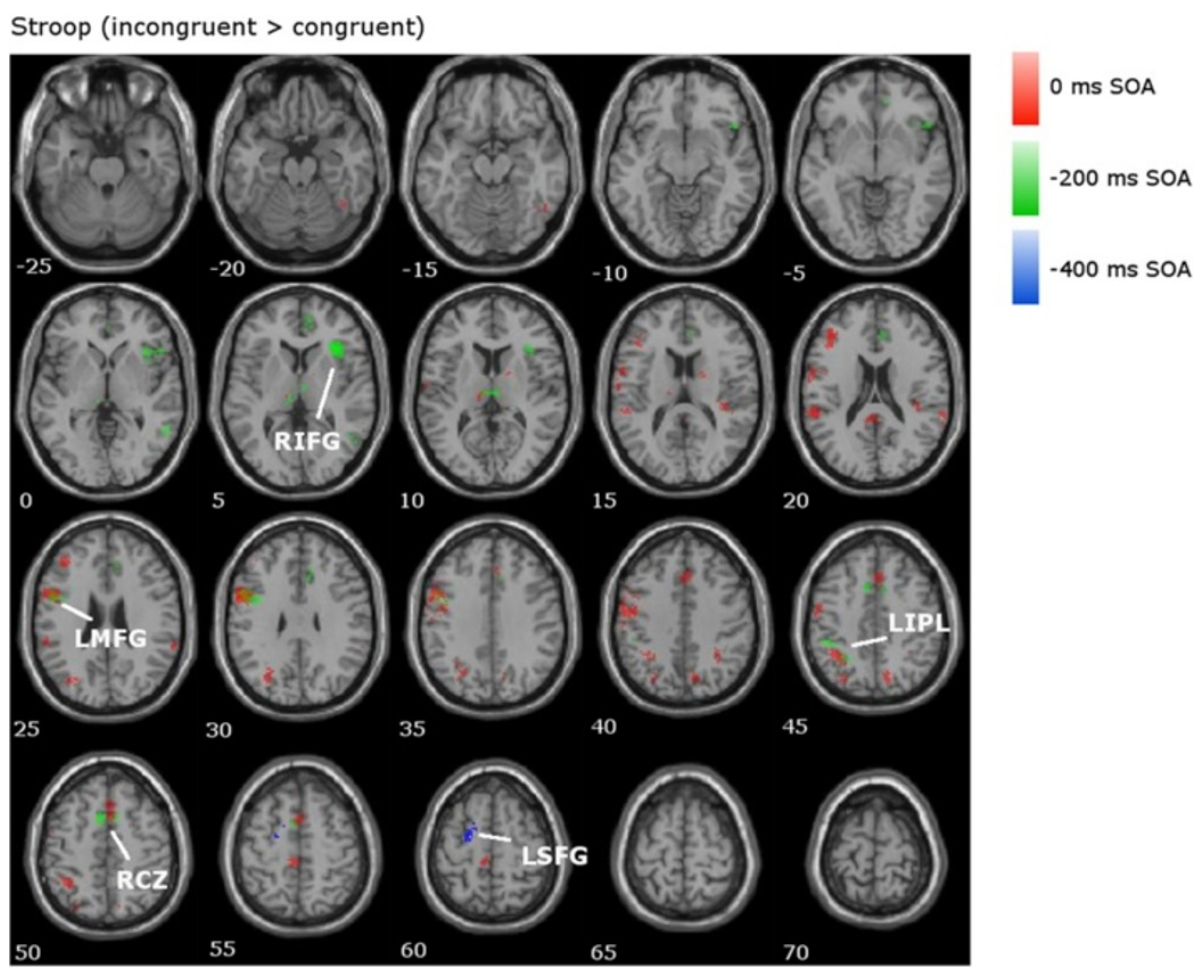

Figure 3 Stroop contrast in the fMRI data. Overlaid contrasts for the Stroop comparison (incongruent > congruent) for all SOAs, with clusters of interest labelled (LIPL = left inferior parietal lobe; $L S F G=$ left superior frontal gyrus). Axial slices are shown from $z=-25$ to $z=70$. 


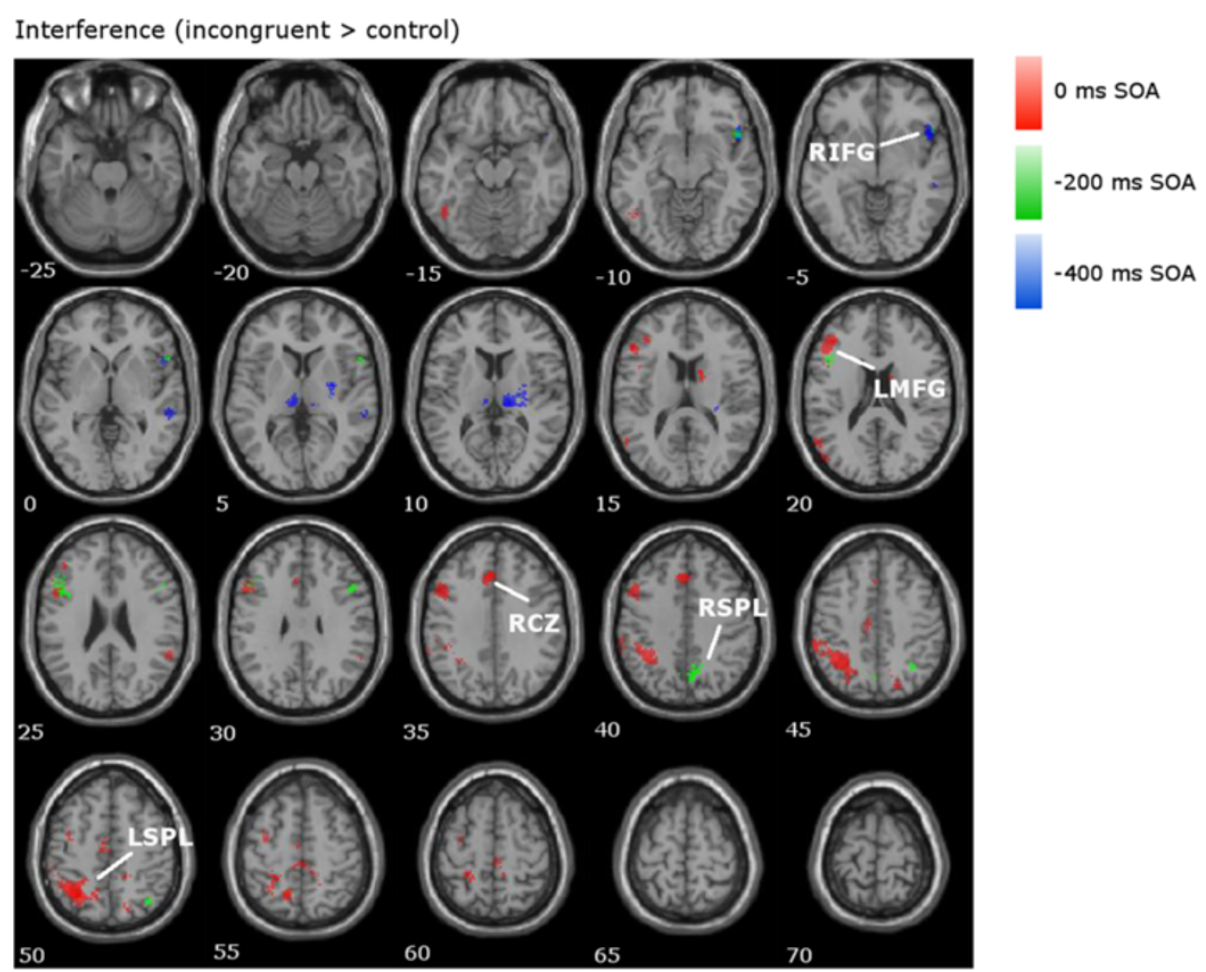

Figure 4 Interference contrast in the fMRI data. Overlaid contrasts for the interference comparison (incongruent > control) for all SOAs, with clusters of interest labelled (LSPL = left superior parietal lobe; $\mathrm{RSPL}=$ right superior parietal lobe).

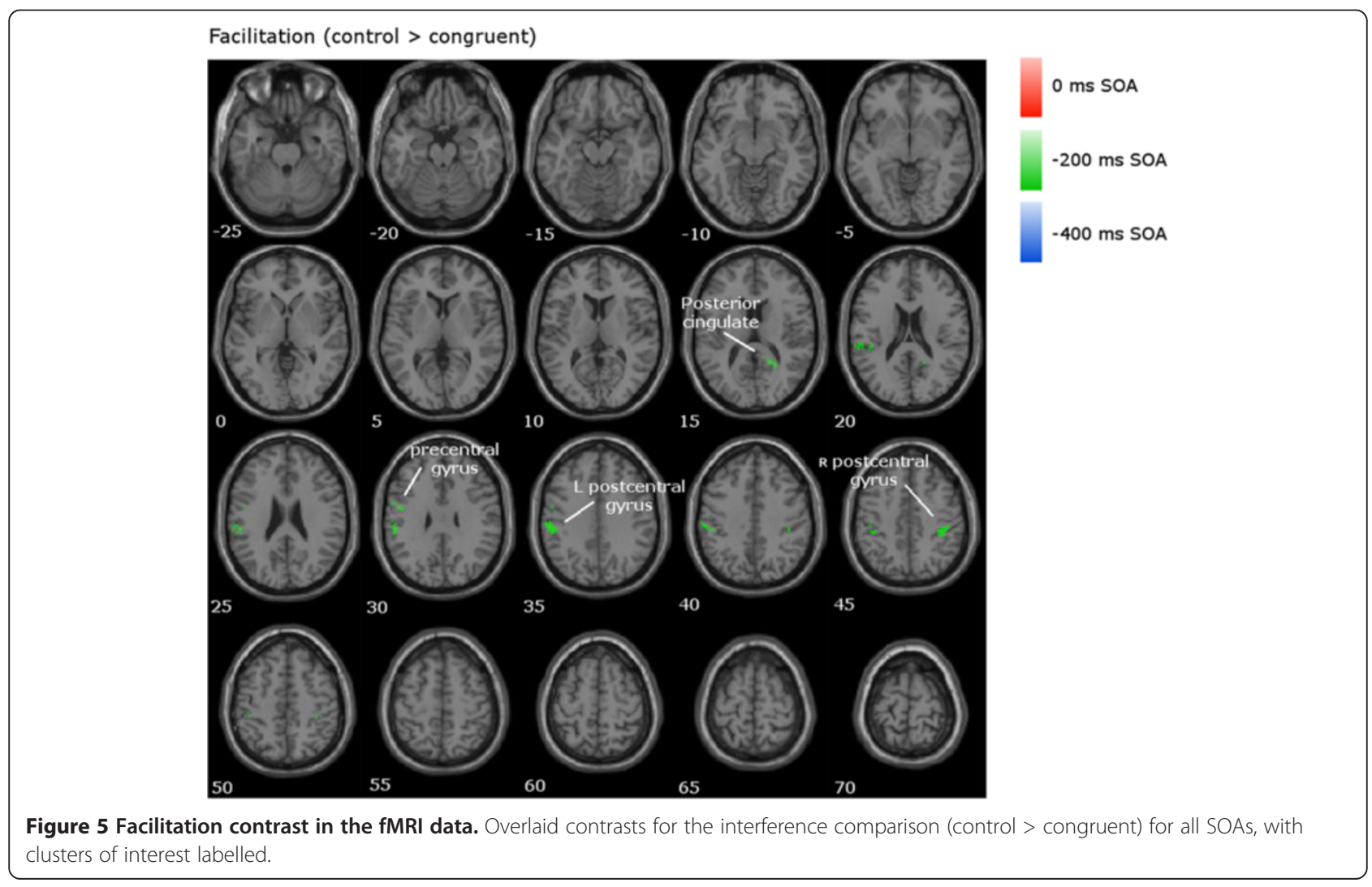


Table 2 Local effects of SOA in the fMRI data

\begin{tabular}{|c|c|c|c|c|c|c|c|}
\hline \multirow{2}{*}{ Contrast } & \multirow{2}{*}{ Region } & \multirow{2}{*}{ BA } & \multicolumn{3}{|c|}{ MNI coordinates } & \multirow{2}{*}{$\begin{array}{l}\text { Cluster } \\
\text { size }\end{array}$} & \multirow{2}{*}{$\begin{array}{c}\text { Peak } \\
\text { Z-score }\end{array}$} \\
\hline & & & $\mathrm{x}$ & $y$ & $z$ & & \\
\hline Stroop effect & No voxels surviving thresholding & -- & -- & -- & -- & -- & - \\
\hline \multirow[t]{4}{*}{ Interference effect } & R precuneus/superior parietal lobe & 7 & 12 & -62 & 40 & 282 & 4.36 \\
\hline & L medial frontal gyrus/RCZ & 8 & -6 & 28 & 38 & 101 & 3.80 \\
\hline & R paracentral lobule & $5 / 3$ & 16 & -40 & 54 & 65 & 4.30 \\
\hline & R superior frontal gyrus & 9 & 22 & 48 & 36 & 54 & 4.19 \\
\hline Facilitation effect & R inferior parietal lobule/postcentral gyrus & $40 / 2$ & 38 & -32 & 44 & 32 & 3.66 \\
\hline
\end{tabular}

Legend: Results of the 3-way (SOA) ANOVAs identifying local effects of SOA on Stroop, interference, and facilitation effect magnitude, with a threshold of $p<0.001$ and clusters $>30$ voxels.
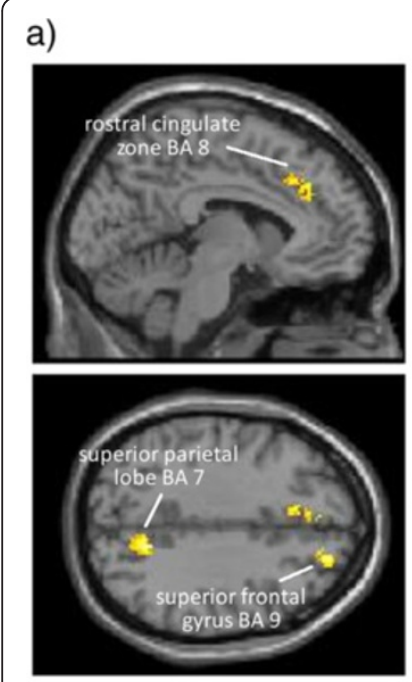

c)
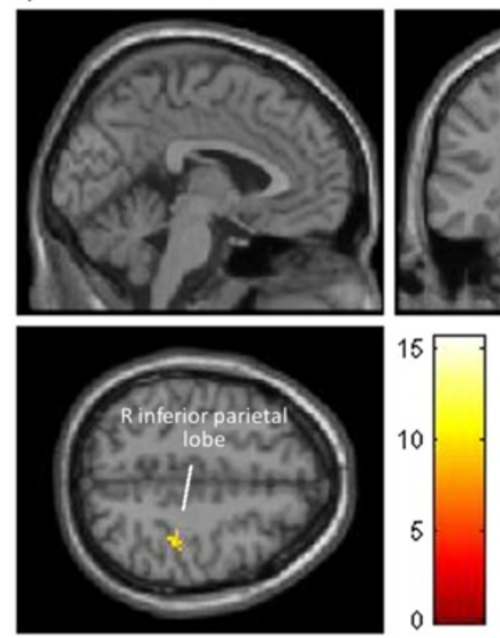

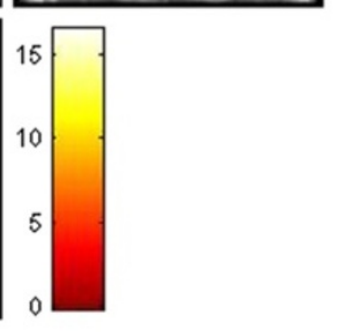

b)
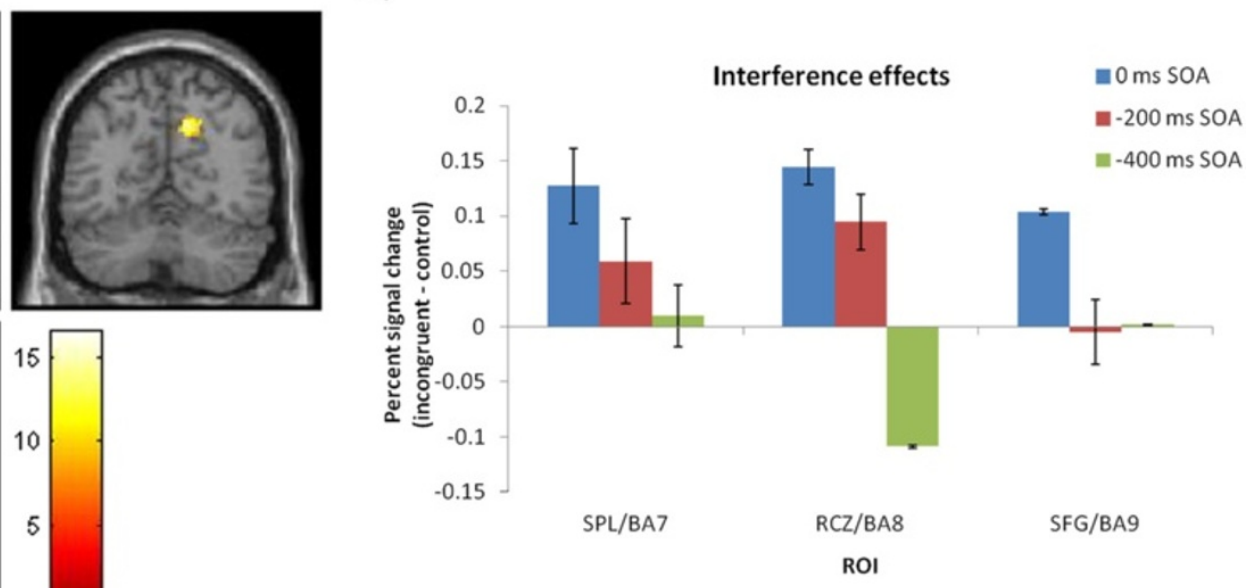

d)
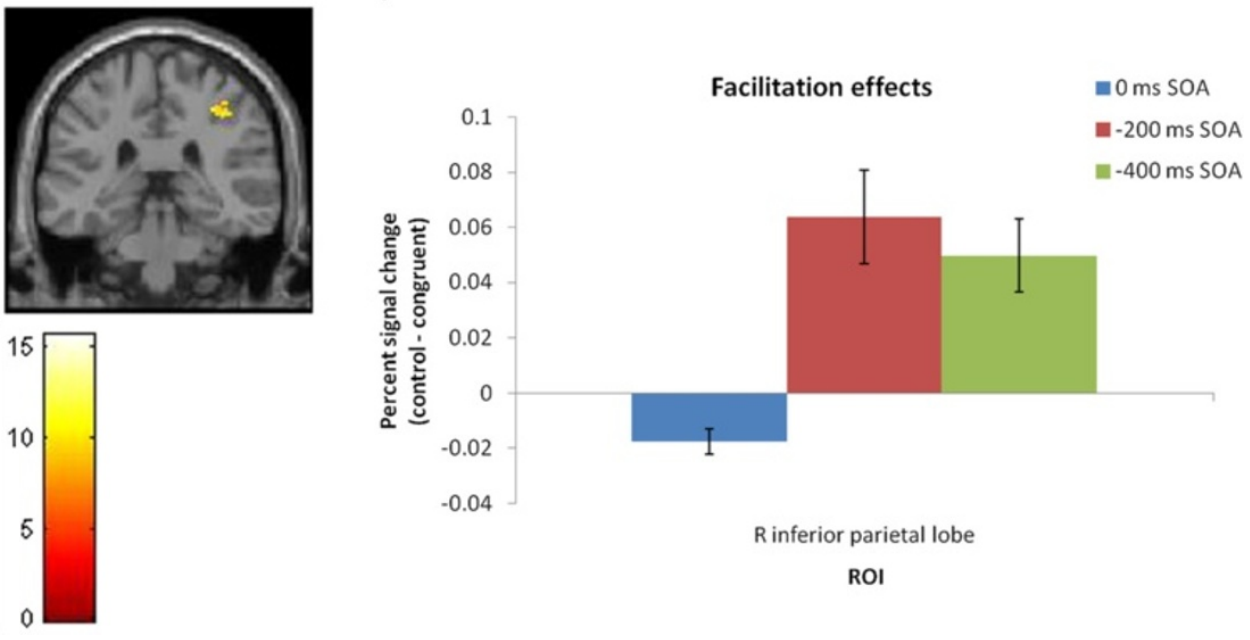

Figure 6 Interaction of interference and SOA in the fMRI data. Results of the 3-way ANOVA identifying significant interactions of a) interference and c) facilitation magnitude with SOA, with ROIs indicated. Panels to the right show the percent signal change effect in b) interference (incongruent signal change minus control signal change) and d) facilitation (control signal change minus congruent signal change) for each $\mathrm{ROI}$ and SOA. 


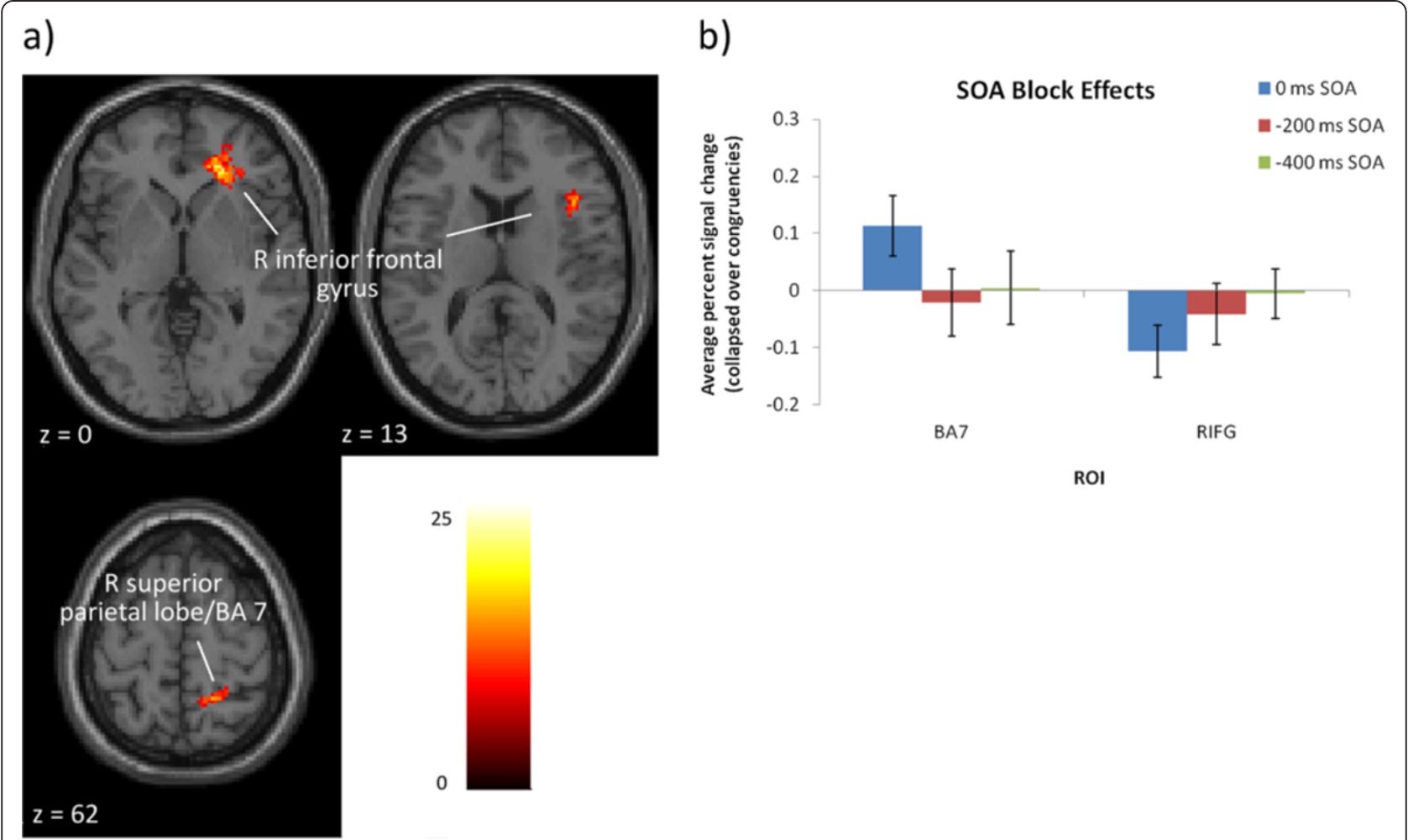

Figure 7 Global SOA effects in the fMRI data. Results of the 3-way ANOVA collapsing across congruency to investigate global (i.e. block-wide) SOA effects. a) Axial slices presented at three z-coordinates to illustrate two distinct clusters in the right inferior frontal gyrus, as well as a cluster in the superior parietal lobe. b) The percent signal change for each ROI and SOA, collapsed over congruency (the RIFG percent signal change was extracted from the larger cluster at $z=0$ ).

confirmed by the presence of differences in the overall level of activation in each SOA.

To further investigate global effects of SOA, each congruency was compared between SOAs using two-sample $t$-tests (e.g. $-400 \mathrm{~ms}$ congruent $>0 \mathrm{~ms}$ congruent; Table 4). Due to the pre-exposure of the word in negative SOAs, visual activation was expected in these conditions compared to the $0 \mathrm{~ms}$ SOA. The data confirmed this prediction: the $-400 \mathrm{~ms}$ SOA showed more activation than the other SOAs across all congruencies in medial, lateral, and inferior areas of the occipitotemporal gyrus (BAs 17/18/19) and the $-200 \mathrm{~ms}$ SOA incongruent condition activated the lateral occipitotemporal gyrus (BA 36) compared to the $0 \mathrm{~ms}$ SOA. All subsequent analyses focused on activation outside of the occipital cortex. Of particular interest were SOA effects in the congruent and control conditions, which would suggest a conflict-independent effect of SOA on response priming and/or strategic attention.

The full results are presented in Table 4. To summarize the most important effects, which will be further interpreted with specific regards to response priming effects and strategic attentional control in the Discussion, the $-200 \mathrm{~ms}$ SOA elicited stronger activation compared to the $0 \mathrm{~ms}$ SOA for the congruent and control conditions in the left superior/middle frontal gyrus (BA 9). The $-400 \mathrm{~ms}$ SOA control condition activated the RIFG to a greater extent than the $0 \mathrm{~ms}$ SOA control

Table 3 Global effects of SOA in the fMRI data

\begin{tabular}{|c|c|c|c|c|c|c|c|}
\hline \multirow{2}{*}{ Contrast } & \multirow{2}{*}{ Region } & \multirow{2}{*}{$B A(s)$} & \multicolumn{3}{|c|}{ MNI coordinates } & \multirow{2}{*}{$\begin{array}{c}\text { Cluster } \\
\text { size }\end{array}$} & \multirow{2}{*}{$\begin{array}{c}\text { Peak } \\
\text { Z-score }\end{array}$} \\
\hline & & & $x$ & $y$ & $z$ & & \\
\hline \multirow[t]{3}{*}{ Block-wide SOA effect } & R ACC/inferior frontal gyrus & $32 / 47$ & 16 & 38 & 0 & 310 & 5.32 \\
\hline & R inferior frontal gyrus & 45 & 42 & 20 & 10 & 104 & 4.38 \\
\hline & R superior parietal lobe & 7 & 18 & -48 & 62 & 75 & 4.41 \\
\hline
\end{tabular}

Legend: Results of the 3-way ANOVA identifying global effects of SOA manipulation by collapsing across congruency in each SOA block, with a threshold of $p<0.001$ and clusters $>30$ voxels. 
Table 4 Between-condition comparisons across SOAs of the Stroop task (clusters $>30$ voxels) for each congruency condition

\begin{tabular}{|c|c|c|c|c|c|c|c|c|}
\hline \multirow{2}{*}{$\begin{array}{l}\text { Congruency } \\
\text { condition }\end{array}$} & \multirow{2}{*}{ Contrast } & \multirow{2}{*}{ Region } & \multirow{2}{*}{$\mathrm{BA}(\mathrm{s})$} & \multicolumn{3}{|c|}{ MNI coordinates } & \multirow{2}{*}{$\begin{array}{l}\text { Cluster } \\
\text { size }\end{array}$} & \multirow{2}{*}{$\begin{array}{c}\text { Peak } \\
\text { Z-score }\end{array}$} \\
\hline & & & & $\mathbf{x}$ & $y$ & $z$ & & \\
\hline \multirow[t]{11}{*}{ Congruent } & $0 \mathrm{~ms}>-200 \mathrm{~ms}$ & No voxels surviving thresholding & -- & - & -- & -- & -- & -- \\
\hline & $-200 \mathrm{~ms}>0 \mathrm{~ms}$ & L insula & 13 & -40 & 4 & -8 & 85 & 3.76 \\
\hline & & L insula/postcentral gyrus & $13 / 45$ & -42 & -12 & 20 & 45 & 3.98 \\
\hline & & L superior/middle frontal gyrus & 9 & -14 & 50 & 22 & 44 & 3.76 \\
\hline & & $L$ inferior frontal gyrus & $45 / 47 / 13$ & -48 & 16 & 4 & 43 & 3.91 \\
\hline & $0 \mathrm{~ms}>-400 \mathrm{~ms}$ & R superior parietal lobule/postcentral gyrus & 7 & 22 & -46 & 62 & 46 & 3.78 \\
\hline & & L postcentral gyrus & $2 / 40$ & -40 & -36 & 60 & 39 & 3.77 \\
\hline & $-400 \mathrm{~ms}>0 \mathrm{~ms}$ & $\mathrm{~L}$ insula/inferior frontal gyrus/precentral gyrus & $13 / 38$ & -46 & 12 & 2 & 105 & 3.91 \\
\hline & & L middle/inferior occipital gyrus & 18 & -26 & -84 & -2 & 75 & 3.85 \\
\hline & $-200 \mathrm{~ms}>-400 \mathrm{~ms}$ & No voxels surviving thresholding & -- & -- & -- & -- & -- & -- \\
\hline & $-400 \mathrm{~ms}>-200 \mathrm{~ms}$ & No voxels surviving thresholding & -- & -- & -- & -- & -- & -- \\
\hline \multirow[t]{16}{*}{ Control } & $0 \mathrm{~ms}>-200 \mathrm{~ms}$ & No voxels surviving thresholding & -- & -- & -- & -- & -- & -- \\
\hline & $-200 \mathrm{~ms}>0 \mathrm{~ms}$ & L parahippocampal gyrus & - & -32 & -24 & -14 & 77 & 4.22 \\
\hline & & $\mathrm{L}$ superior frontal gyrus & 9 & -14 & 46 & 22 & 45 & 4.77 \\
\hline & & L ACC & 32 & -14 & 22 & 18 & 34 & 4.21 \\
\hline & & L insula/postcentral gyrus & 13 & -40 & -10 & 22 & 34 & 4.04 \\
\hline & $0 \mathrm{~ms}>-400 \mathrm{~ms}$ & No voxels surviving thresholding & -- & -- & -- & -- & -- & -- \\
\hline & $-400 \mathrm{~ms}>0 \mathrm{~ms}$ & L lingual gyrus/medial occipitotemporal gyrus & $18 / 17$ & -26 & -84 & -2 & 452 & 4.71 \\
\hline & & R lingual gyrus/lateral occipitotemporal gyrus & 18 & 22 & -76 & -2 & 92 & 4.14 \\
\hline & & R inferior frontal gyrus/insula & $47 / 45$ & 44 & 16 & -8 & 87 & 3.91 \\
\hline & & L inferior frontal gyrus/insula/inferior temporal gyrus & $47 / 38$ & -40 & 14 & -12 & 51 & 3.89 \\
\hline & & R fusiform gyrus/lateral occipitotemporal gyrus & 19 & 38 & -68 & -8 & 46 & 3.86 \\
\hline & & $\mathrm{L}$ middle/inferior frontal gyrus & $10 / 47$ & -32 & 36 & 8 & 43 & 4.19 \\
\hline & & R parahippocampal gyrus/medial occipitotemporal gyrus & 19 & 26 & -54 & -2 & 33 & 3.77 \\
\hline & $-200 m s>-400 m s$ & R posterior cingulate & $23 / 29$ & 4 & -36 & 18 & 89 & 4.12 \\
\hline & & R posterior cingulate gyrus/angular gyrus & 31 & 24 & -44 & 38 & 82 & 4.88 \\
\hline & $-400 m s>-200 m s$ & No voxels surviving thresholding & -- & -- & -- & -- & -- & -- \\
\hline \multirow[t]{8}{*}{ Incongruent } & $0 \mathrm{~ms}>-200 \mathrm{~ms}$ & No voxels surviving thresholding & -- & -- & -- & -- & -- & -- \\
\hline & $-200 \mathrm{~ms}>0 \mathrm{~ms}$ & L posterior cingulate gyrus & 31 & -18 & -40 & 34 & 73 & 4.54 \\
\hline & & L parahippocampal gyrus/lateral occipitotemporal gyrus & 36 & -30 & -32 & -10 & 69 & 4.36 \\
\hline & $0 \mathrm{~ms}>-400 \mathrm{~ms}$ & $\mathrm{R}$ posterior cingulate gyrus & 31 & 24 & -44 & 38 & 40 & 4.27 \\
\hline & & L cuneus/superior occipital gyrus & 19/18 & -4 & -88 & 30 & 38 & 4.44 \\
\hline & $-400 \mathrm{~ms}>0 \mathrm{~ms}$ & $\mathrm{~L}$ middle occipital gyrus & 18 & -26 & -84 & -2 & 35 & 3.74 \\
\hline & $-200 \mathrm{~ms}>-400 \mathrm{~ms}$ & $\mathrm{R}$ posterior cingulate gyrus & 31 & 24 & -44 & 38 & 72 & 4.47 \\
\hline & $-400 \mathrm{~ms}>-200 \mathrm{~ms}$ & R parahippocampal gyrus & 28 & 20 & -14 & -22 & 36 & 4.42 \\
\hline
\end{tabular}

condition. The $-200 \mathrm{~ms}$ SOA incongruent and control conditions activated the posterior cingulate more than these congruencies in other SOAs. The congruent and incongruent conditions showed enhanced right superior parietal lobe (BA 7) and posterior cingulate activation in the $0 \mathrm{~ms}$ SOA compared to the $-400 \mathrm{~ms}$ SOA. Finally, the $-400 \mathrm{~ms}$ SOA congruent and control conditions, and the $-200 \mathrm{~ms}$ SOA congruent condition, activated the
LIFG to a greater extent than the corresponding congruencies in the $0 \mathrm{~ms}$ SOA.

\section{Discussion}

The current study employed fMRI to investigate for the first time how the executive control network is modulated by SOA in a Stroop task. Of particular interest were 1) the neural effects of SOA on interference and 
facilitation effects; 2) response priming in negative SOAs; and 3) the effects of blocked SOA presentation on strategic orientation of attention. To briefly summarize the results that will be discussed at length in the next sections, four areas in the executive control network were sensitive to trial-specific SOA effects on interference. An overall ANOVA investigating the global, congruency-independent effects of SOA demonstrated that the RIFG was sensitive to response priming effects in negative SOAs, whereas the right superior parietal lobe (BA 7) was sensitive to attentional effects of blocked SOA presentation.

\section{SOA modulation of interference and facilitation effects}

Previous work with SOA manipulation in the Stroop task has documented varying amounts of interference and facilitation in each SOA. Behaviourally, the current data replicated prior observations that, in a manual task, peak interference occurred at the $-200 \mathrm{~ms}$ SOA and was also significant at the $0 \mathrm{~ms}$ SOA [38-40]. Facilitation was similar between the $-400 \mathrm{~ms}$ and $-200 \mathrm{~ms}$ SOAs, which also replicates previous literature $[38,41,43,44]$. Importantly, the effects of SOA on the magnitudes of interference and facilitation effects suggest differences in executive control strategies or recruitment in each SOA, which was investigated with fMRI for the first time in the current study.

Analyses indicated that areas of the brain participating in Stroop effects were not strongly modulated by SOA. However, three areas of the cognitive control network were sensitive to the effects of SOA on interference: the right superior parietal lobe (BA 7), RCZ (BA 8), and superior frontal gyrus (BA 9). Percent signal change analyses indicated that these areas showed greater BOLD change for the $0 \mathrm{~ms}$ and $-200 \mathrm{~ms}$ SOAs than the $-400 \mathrm{~ms}$ SOA, suggesting sensitivity to the magnitude of cognitive conflict. Specifically, this indicates that areas involved in performance monitoring (RCZ), conflict resolution (superior frontal gyrus/BA 9), and task-relevant attentional control (superior parietal lobule/BA 7) were most affected by interference during simultaneous stimuli presentation in the $0 \mathrm{~ms}$ SOA. As this SOA showed comparatively smaller behavioural interference effects, the stronger recruitment of these areas may reflect more efficient conflict processing. In contrast, the reduced activation in the $-200 \mathrm{~ms}$ SOA illustrates that conflict resolution mechanisms were not engaged as efficiently, generating larger behavioural effects. In sum, this demonstrates that SOA significantly affected the recruitment of the cognitive control network during interference, as predicted.

When investigating Stroop, interference, and facilitation effects in each SOA individually, the $0 \mathrm{~ms}$ SOA showed a traditional recruitment of the executive control network for Stroop and interference effects, including the RCZ, LMFG, LIFG, and right superior parietal lobe, in line with previous literature $[1,3,4,12,21,23,24]$. The $-200 \mathrm{~ms}$ SOA activated these same areas but to a lesser extent, again suggesting a less-efficient recruitment of cognitive control which generated increased behavioural interference. Therefore the two most cognitivelydemanding SOAs activated a similar neural network, but the amount of activation was modulated by SOA.

Despite the relatively reduced activation in the conflict contrasts of the $-200 \mathrm{~ms}$ SOA, when directly comparing the congruency conditions this SOA showed heightened ACC and LMFG (BA 9) activation in all congruencies, including the control condition. Previous research has reported that the ACC and prefrontal cortex are sensitive to the amount of conflict in a task [29] and that activation can be enhanced with task difficulty across the entire task rather than on a trial-by-trial basis [59]. The observed ACC and LMFG activation therefore suggests that cognitive control was enhanced throughout the $-200 \mathrm{~ms}$ SOA block and in all congruencies due to the heightened cognitive demands in this SOA.

Overall, there was a disparity between the behavioural and neural effects: the $0 \mathrm{~ms}$ SOA elicited stronger brain activity yet experienced smaller behavioural conflict effects, while the opposite was true for the $-200 \mathrm{~ms}$ SOA. This negative association of behavioural and neural responses has been reported previously [60-63] and suggests that successful cognitive control requires more extensive activation of the executive control network to reduce behavioural conflict effects.

The block-wide facilitation ANOVA also demonstrated that a cluster in the right inferior parietal lobe (BA 40) was sensitive to SOA effects on facilitation, and percent signal change analyses confirmed that this area showed greater signal change for the -200 and -400 ms SOAs compared to the $0 \mathrm{~ms}$ SOA. This mirrors the behavioural data, which showed large facilitation effects for the negative SOAs but virtually no facilitation for the $0 \mathrm{~ms}$ SOA, and also supports previous literature finding similar facilitation effects across negative SOAs $[38,41,43,44]$.

When extracting the percent signal change from this cluster in the facilitation effects, the results showed that the negative SOAs showed larger signal change in right BA 40/2 for the control condition than the congruent condition, whereas the $0 \mathrm{~ms}$ SOA showed similar levels of signal change for both congruencies. As mentioned in the Introduction, the parietal lobes are involved in topdown attentional control towards the task-relevant target or attribute [17-20]. It may be that in negative SOAs, pre-exposure of the control stimulus allows the semantic system to evaluate the stimulus and determine that the symbol string has no meaning, such that when the colour appears attention can be more efficiently directed to the target stimulus; this could explain the greater 
activation of the parietal lobe in response to the control stimulus compared to the congruent stimulus. In contrast, in the $0 \mathrm{~ms} \mathrm{SOA}$, simultaneous presentation of stimuli requires that the word be evaluated at the same time the colour is being processed, which may interrupt this efficiency of the parietal lobe. This is a tentative interpretation, however, and more research is needed to fully evaluate the neural correlates of SOA effects on facilitation. Nevertheless, the current results confirm that SOA manipulation does modulate facilitation effects, both behaviourally and in the brain.

In sum, the cognitive control network was sensitive to trial-specific effects of SOA on interference. Specifically, three regions of the network were most active in the $0 \mathrm{~ms}$ SOA, leading to correspondingly smaller behavioural interference effects. In contrast, the $-200 \mathrm{~ms}$ SOA experienced comparatively less neural activation, suggesting less-efficient cognitive control which led to larger behavioural interference effects. This therefore demonstrates that SOA modulates the conflict-processing demands of the executive control network and suggests that short preexposure of the word in the $-200 \mathrm{~ms}$ SOA disrupts the efficient processing of this system.

\section{Response priming effects in negative SOAs}

Appelbaum et al. [40] have suggested that negative SOAs create a response priming effect by pre-activating response selection, which generates larger behavioural interference and facilitation effects compared to the $0 \mathrm{~ms}$ SOA. This study explored the neural representation of these response priming effects in the $-200 \mathrm{~ms}$ and $-400 \mathrm{~ms}$ SOAs. The block-wide SOA analysis identified two regions that were modulated by the global effects of SOA: the RIFG and the right superior parietal lobe. As will be argued here, the RIFG was involved in response priming effects.

In the SOA-specific analyses, the Stroop and interference contrasts in the $-200 \mathrm{~ms}$ SOA elicited RIFG activation to a greater extent than the $0 \mathrm{~ms}$ SOA; additionally, the $-400 \mathrm{~ms}$ SOA activated the RIFG in the interference contrast. As mentioned in the Introduction, the RIFG has been implicated in response inhibition (i.e. inhibiting pre-potent motor responses, as in a no-go paradigm; [13-16]). The activation of this area in negative SOAs suggests its involvement in response priming effects; specifically, the fact that RIFG activation occurred in Stroop and interference contrasts in negative SOAs suggests that this area is involved in applying response inhibition after incorrectly-primed response selection.

To illustrate, in incongruent conditions the pre-exposed word primes (incorrect) response selection, which must then be overcome (via response inhibition mechanisms in the RIFG) to make a correct response to the colour. This would explain why the $-200 \mathrm{~ms}$ SOA generates larger interference and facilitation effects: the need for response inhibition in incongruent conditions leads to longer incongruent RTs and consequently larger behavioural interference effects relative to the other conditions. In congruent conditions, however, the primed response preparation leads to faster RTs and increased behavioural facilitation effects. Response priming in the RIFG can therefore explain the larger interference and facilitation effects observed in the $-200 \mathrm{~ms}$ SOA, as observed in the current data and in previous research [38-40].

In contrast, the $-400 \mathrm{~ms}$ SOA generated large behavioural facilitation effects but no interference, which contradicts the proposal that response priming increases both interference and facilitation effects. In direct comparisons of the individual congruencies in the neural data, the $-400 \mathrm{~ms}$ SOA showed more RIFG activation in the control condition compared to other SOAs. This suggests that the RIFG cannot purely reflect response inhibition in this SOA, because a response cannot be primed in the control condition as it does not contain semantic information.

Although the RIFG has been specifically implicated in response inhibition, previous investigations of the right posterior ventrolateral prefrontal cortex, which includes the RIFG, have indicated that this area is involved more generally in updating action plans, a function which includes, but is not limited to, response inhibition $[13-16,49,64,65]$. The current data in the $-400 \mathrm{~ms}$ SOA support this more general role of the RIFG in action updating. To illustrate, although the pre-exposure of the word primes response selection, the long pre-exposure may allow sufficient time to fully inhibit the motor response, as the word is a non-target stimulus: this would explain the lack of behavioural interference in the $-400 \mathrm{~ms}$ SOA. If the primed response is fully inhibited, this would also predict a reduction in facilitation effects; however, facilitation is increased in this SOA. Therefore in addition to response inhibition, the RIFG may also perform more general action updating, as proposed by previous literature, which readies the motor system to make a response. If response preparation mechanisms are primed in a $-400 \mathrm{~ms}$ SOA, upon subsequent colour presentation the system benefits from the convergent information in the congruent condition (therefore generating large facilitation effects) but the incongruent condition does not cause any additional conflict (resulting in little or no interference). In both congruencies, similar brain regions are active, which may explain the lack of neural differences between these conditions in the current $-400 \mathrm{~ms}$ SOA data.

Thus, the current data can be explained by assuming that in the $-200 \mathrm{~ms}$ SOA the RIFG is engaged primarily for response inhibition in incongruent conditions, as a result of the response priming effect, 
whereas in the $-400 \mathrm{~ms}$ SOA the RIFG is involved in more general action updating. Importantly, in the $-200 \mathrm{~ms}$ SOA the increased interference occurs because the response priming effect does not have enough time to be resolved. Lexical access occurs approximately $200 \mathrm{~ms}$ after word onset (e.g. $[66,67])$, meaning that the colour appears at the same approximate time that semantic activation occurs in this SOA, leaving little extra time for stimulus suppression before conflict arrives. As a result, there is not enough time to overcome the response priming in the incongruent condition before the colour arrives, creating conflict and requiring the RIFG to perform response inhibition. In contrast, in the $-400 \mathrm{~ms}$ SOA there is ample time for both semantic activation of the word and subsequent suppression of the primed response (via the RIFG), which explains the lack of behavioural interference. As well as inhibiting the primed response, the RIFG also performs a more general function of action updating, priming the system to make a motor response. This is a tentative explanation, as the RIFG has also been implicated in other cognitive functions such as reorienting [68], the detection of salient cues [15], and stopping motor actions [27]. However, the current data fits best with an explanation of the RIFG as involved in response inhibition and updating action plans $[13-16,49,64,65]$. Therefore the current data supported Appelbaum et al. [40]'s proposal of response priming with word pre-exposure and also provided additional knowledge of how this mechanism functions in each SOA.

\section{Effects of blocked SOA presentation}

The current study additionally investigated whether blocked SOA presentation would create a global effect of attentional orientation such that the temporal predictability could be used to direct attention to the upcoming target stimulus [41,48]. Such effects should be apparent across the entire block. As mentioned, the global (congruency-independent) analysis of SOA effects revealed two clusters of activation: the RIFG (which has been attributed to response priming effects of response inhibition and action updating $[13-16,49,64,65])$ and the right superior parietal lobe (BA 7). As BA 7 is involved in top-down attentional control [17-20] this area may have been sensitive to attentional control effects resulting from the temporal predictability of blocked SOAs.

It was expected that attentional control effects would be most prominent in negative SOAs, as the word preexposure might act as a temporal cue that the target colour would soon appear. However, the percent signal change analyses illustrated that BA 7 was most active for the $0 \mathrm{~ms}$ SOA. This could suggest that when stimuli are simultaneously presented, attention to the relevant stimulus (the colour) is enhanced in order to facilitate response selection. For example, Egner and Hirsch [61] have suggested that conflict resolution proceeds via amplification of task-relevant attributes; enhanced attentional control in the $0 \mathrm{~ms}$ SOA may therefore indicate a strategy of directed attention towards the colour in order to overcome the effects of the distracting word stimulus. In contrast, the pre-exposure of the word in the negative SOAs may disrupt this process, leading to less activation in BA 7. Interestingly, the enhanced activation of this area for the $0 \mathrm{~ms}$ SOA mirrors the findings of Appelbaum et al. [48], who reported a larger $\mathrm{N}_{\text {inc }}$ in the 0 ms SOA with blocked SOA presentation.

Block-wide strategic attention effects were also identified in the direct comparisons of congruencies across SOA blocks: specifically, the $-200 \mathrm{~ms}$ SOA showed more activation in the posterior cingulate. While being assigned to a number of cognitive roles, one function of the posterior cingulate is in anticipating the need to spatially allocate attention [69]. This could suggest an attentional priming effect in the $-200 \mathrm{~ms}$ SOA such that the short pre-exposure of the word acted as a cue for attentional engagement. It is unclear why a similar effect did not occur in the $-400 \mathrm{~ms} \mathrm{SOA}$; one possibility is that the longer word pre-exposure allowed ample time for the suppression of the word information, so attentional allocation was not prioritized.

In summary, the right superior parietal lobe was sensitive to the effects of blocked SOA presentation, demonstrating that attentional control was modulated by the global effects of SOA. These effects were enhanced for the $0 \mathrm{~ms}$ SOA, which could suggest that attentional mechanisms of conflict resolution were engaged during simultaneous stimulus presentation in the $0 \mathrm{~ms}$ SOA. In addition, SOA effects in the posterior cingulate in the $-200 \mathrm{~ms}$ SOA could reflect an anticipation of attentional control.

In general, the fact that global effects of SOA were observed in regions involved in attentional control supports the proposal of strategic orientation of attention with blocked SOA presentation. However, these are ultimately tentative interpretations in light of the fact that a mixed-SOA comparison condition was not included in order to fully test the effects of strategic attentional orientation. For example, if blocked SOA affects attentional orienting towards the relevant dimension, this effect should be diminished with mixed SOAs, leading to smaller interference at negative SOAs as compared to blocked presentation. Therefore mixed SOA presentation might lead to very different effects, both in the behavioural data and in the neural recruitment of the attentional control network [48]. As this was the first study to use the Stroop SOA paradigm with fMRI, the comparison of blocked vs. mixed SOAs, and how this paradigm choice affects the recruitment of conflict processing mechanisms, requires further exploration. 


\section{Distractor suppression effects in negative SOAs}

In addition to the reported effects of SOA on conflict processing, response priming, and attentional control, one additional finding was that the LIFG was generally more active across all congruencies for negative SOAs. Specifically, more LIFG activation was observed for the $-400 \mathrm{~ms}$ SOA congruent and control conditions and the -200 ms SOA congruent condition as compared to the corresponding congruencies in the $0 \mathrm{~ms}$ SOA. Previous research has suggested that within the cognitive control network the LIFG performs suppression of irrelevant information (e.g. [12]); this finding of enhanced LIFG activation throughout the negative SOAs may therefore suggest a strategy of distractor suppression. For instance, at the time of word presentation in negative SOAs the word's eventual congruency is unknown, as the colour has not yet appeared to cause conflict. Therefore the LIFG may be suppressing all pre-exposed information, as it is irrelevant to the task, in order to avoid potential conflict when the colour appears. Importantly, the control condition also elicited enhanced LIFG activation in negative SOAs, suggesting that this mechanism is neither conflict- nor linguistically-specific, but is a global strategy of task-irrelevant distractor suppression.

This proposal of a distractor suppression mechanism in negative SOAs suggests a strategy of proactive cognitive control, which draws a parallel to the dual mechanisms of control theory put forth by Braver and colleagues [70-72]. This theory proposes that cognitive control consists of two mechanisms: one reactive, which is a 'late correction' response that uses context information transiently to resolve conflict once it has occurred; and one proactive, which uses an 'early selection' strategy to actively sustain goal-relevant information and pre-emptively reduce control demands when conflict occurs. The fact that LIFG activation occurred across all congruencies in negative SOAs suggests a sustained activation of this structure, potentially through a mechanism of proactive cognitive control. In contrast, reactive control may be more characteristic of the $0 \mathrm{~ms} \mathrm{SOA}$, in which suppression must be activated anew on every trial. Although a tentative explanation, this proposal of distractor suppression by the LIFG suggests a proactive strategy employed to lessen the influence of the non-target stimulus and highlights the dynamic nature of the executive control system in response to various cognitive demands.

\section{Conclusions}

In summary, the current data demonstrated both trialspecific and block-wide effects of SOA on the recruitment and behaviour of the executive control network. The network was activated to different extents in each SOA, with the largest neural interference effects in the $0 \mathrm{~ms}$ SOA compared to the $-200 \mathrm{~ms}$ SOA. As the $0 \mathrm{~ms}$
SOA demonstrated relatively reduced behavioural interference effects, this more extensive neural activation suggests more efficient conflict processing, whereas in the $-200 \mathrm{~ms}$ SOA this efficient processing was disrupted by the pre-exposure of the word. Response priming effects were localized to the RIFG; in the $-200 \mathrm{~ms}$ SOA in particular, these effects can be explained by response inhibition in incongruent conditions in order to overcome the conflict created by the incorrectly primed response. In the $-400 \mathrm{~ms} \mathrm{SOA}$, with longer word pre-exposure, the RIFG activation suggested more general response preparation and action updating, leading to increased behavioural facilitation but no interference. Strategic attention effects were localized to the right superior parietal lobe but were enhanced in the $0 \mathrm{~ms}$ SOA, suggesting that negative SOAs do not create a temporal cue; instead, attentional control mechanisms are enhanced in the $0 \mathrm{~ms}$ SOA to more efficiently deal with the conflict generated by simultaneous stimulus preexposure. Finally, word pre-exposure in the negative SOAs also appeared to recruit a proactive control strategy of distractor suppression, localized to the LIFG. As this was the first study to explore SOA modulation in the Stroop task with fMRI, there are ample possibilities for future research. However, the use of SOA manipulation has provided valuable information on the malleable and dynamic nature of cognitive control.

\section{Endnote}

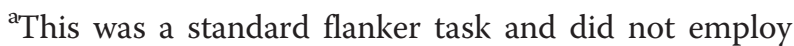
SOA manipulation. As the focus of this data is on the modulation of the cognitive control network with SOA manipulation in the Stroop task, the data from the flanker task are not reported here.

\section{Competing interests}

The authors declare that they have no competing interests.

\section{Authors' contributions}

EC participated in the conception and design of the study, collected the data, performed the statistical analysis, and drafted the manuscript. $\mathrm{WH}$ participated in the conception and design, helped with interpretation of the data, and helped with revising the manuscript. Both authors read and approved the final manuscript.

Received: 6 February 2013 Accepted: 31 July 2013

Published: 31 July 2013

\section{References}

1. Ridderinkhof KR, Ullsperger M, Crone EA, Nieuwenhuis S: The role of the medial frontal cortex in cognitive control. Science 2004, 306:443-447

2. Botvinick MM, Cohen JD, Carter CS: Conflict monitoring and anterior cingulate cortex: an update. Trends Cogn Sci 2004, 8:539-546.

3. Botvinick MM, Braver TS, Barch DM, Carter CS, Cohen JD: Conflict monitoring and cognitive control. Psychol Rev 2001, 108:624-652.

4. van Veen V, Carter CS: The anterior cingulate as a conflict monitor: fMRI and ERP studies. Physiol Behav 2002, 77:477-482.

5. Roelofs A, van Turennout M, Coles MGH: Anterior cingulate cortex activity can be independent of response conflict in Stroop-like tasks. Proc Natl Acad Sci 2006, 103:13884-13889. 
6. Aarts E, Roelofs A, van Turennout M: Anticipatory activity in anterior cingulate cortex can be independent of conflict and error likelihood. J Neurosci 2008, 28:4671-4678.

7. Mansouri FA, Tanaka K, Buckley MJ: Conflict-induced behavioural adjustment: a clue to the executive functions of the prefrontal cortex. Nat Rev Neurosci 2009, 10:141-152.

8. Carter C, van Veen V: Anterior cingulate cortex and conflict detection: an update of theory and data. Cogn Affect Behav Neurosci 2007, 7:367-379.

9. Novick JM, Kan IP, Trueswell JC, Thompson-Schill SL: A case for conflict across multiple domains: memory and language impairments following damage to ventrolateral prefrontal cortex. Cogn Neuropsychol 2009, 26:527-567.

10. Novick JM, Trueswell JC, Thompson-Schill SL: Cognitive control and parsing: reexamining the role of Broca's area in sentence comprehension. Cogn Affect Behav Neurosci 2005, 5:263-281.

11. Thompson-Schill SL, Kurtz KJ, Gabrieli JDE: Effects of semantic and associative relatedness on automatic priming. J Mem Lang 1998, 38:440-458

12. Ye Z, Zhou X: Conflict control during sentence comprehension: $\mathrm{fMR}$ evidence. Neuroimage 2009, 48:280-290.

13. Aron AR, Robbins TW, Poldrack RA: Inhibition and the right inferior frontal cortex. Trends Cogn Sci 2004, 8:170-177.

14. Garavan H, Ross TJ, Stein EA: Right hemispheric dominance of inhibitory control: an event-related functional MRI study. Proc Natl Acad Sci 1999, 96:8301-8306

15. Hampshire A, Chamberlain S, Monti M: The role of the right inferior frontal gyrus: inhibition and attentional control. Neuroimage 2010, 50:1313-1319.

16. Levy BJ, Wagner AD: Cognitive control and right ventrolateral prefrontal cortex: reflexive reorienting, motor inhibition, and action updating Ann N Y Acad Sci 2011, 1224:40-62.

17. Corbetta M, Miezin FM, Shulman GL, Petersen SE: A PET study of visuospatial attention. J Neurosci 1993, 13:1202-1226.

18. Culham JC, Kanwisher NG: Neuroimaging of cognitive functions in human parietal cortex. Curr Opin Neurobiol 2001, 11:157-163.

19. Milham MP, Banich MT, Barad V: Competition for priority in processing increases prefrontal cortex's involvement in top-down control: an event-related fMRI study of the stroop task. Cogn Brain Res 2003, 17:212-222.

20. Rushworth MF, Ellison A, Walsh V: Complementary localization and lateralization of orienting and motor attention. Nat Neurosci 2001, 4:656-661.

21. Ridderinkhof KR, van den Wildenberg WPM, Segalowitz SJ, Carter CS: Neurocognitive mechanisms of cognitive control: the role of prefrontal cortex in action selection, response inhibition, performance monitoring, and reward-based learning. Brain Cogn 2004, 56:129-140.

22. Seeley WW, Menon V, Schatzberg AF, Keller J, Glover GH, Kenna H, Reiss AL, Greicius MD: Dissociable intrinsic connectivity networks for salience processing and executive control. J Neurosci 2007, 27:2349-2356.

23. Niendam TA, Laird AR, Ray KL, Dean YM, Glahn DC, Carter CS: Metaanalytic evidence for a superordinate cognitive control network subserving diverse executive functions. Cogn Affect Behav Neurosci 2012, 12:241-268

24. Nee DE, Wager TD, Jonides J: Interference resolution: insights from a meta-analysis of neuroimaging tasks. Cogn Affect Behav Neurosci 2007, 7:1-17.

25. Banich MT: Executive function: the search for an integrated account. Curr Dir Psychol Sci 2009, 18:89-94.

26. Koechlin E, Summerfield C: An information theoretical approach to prefrontal executive function. Trends Cogn Sci 2007, 11:229-235.

27. Sharp DJ, Bonnelle V, De Boissezon X, Beckmann CF, James SG, Patel MC Mehta MA: Distinct frontal systems for response inhibition, attentional capture, and error processing. Proc Natl Acad Sci 2010, 107:6106-6111.

28. Carter CS, Macdonald AM, Botvinick MM, Ross LL, Stenger VA, Noll D, Cohen JD: Parsing executive processes: strategic vs. evaluative functions of the anterior cingulate cortex. Proc Natl Acad Sci 2000, 97:1944-1948.

29. Barch DM, Braver TS, Sabb FW, Noll DC: Anterior cingulate and the monitoring of response conflict: evidence from an $\mathrm{fMRI}$ study of overt verb generation. J Cogn Neurosci 2000, 12:298-309.

30. van Heuven WJB, Schriefers H, Dijkstra T, Hagoort P: Language conflict in the bilingual brain. Cereb Cortex 2008, 18:2706-2716.
31. Stroop J: Studies of interference in serial verbal reactions. J Exp Psychol Gen 1935, 18:643-662.

32. Fan J, Flombaum Jl, McCandliss BD, Thomas KM, Posner Ml: Cognitive and brain consequences of conflict. Neuroimage 2003, 18:42-57.

33. Liu X, Banich MT, Jacobson BL, Tanabe JL: Common and distinct neural substrates of attentional control in an integrated Simon and spatial Stroop task as assessed by event-related fMRI. Neuroimage 2004 22:1097-1106

34. Peterson BS, Skudlarski P, Gatenby JC, Zhang H, Anderson AW, Gore JC: An fMRI study of stroop word-color interference: evidence for cingulate subregions subserving multiple distributed attentional systems. Biol Psychiatry 1999, 45:1237-1258.

35. Peterson BS, Kane MJ, Alexander GM, Lacadie C, Skudlarski P, Leung HC, May J, Gore JC: An event-related functional MRI study comparing interference effects in the Simon and Stroop tasks. Cogn Brain Res 2002, 13:427-440

36. Barch DM, Braver TS, Akbudak E, Conturo T, Ollinger J, Snyder AZ: Anterior cingulate cortex and response conflict: effects of response modality and processing domain. Cereb Cortex 2001, 11:837-848.

37. Kim C, Chung C, Kim J: Multiple cognitive control mechanisms associated with the nature of conflict. Neurosci Lett 2010, 476:156-160.

38. Glaser MO, Glaser WR: Time course analysis of the Stroop phenomenon. J Exp Psychol Hum Percept Perform 1982, 8:875-894.

39. Coderre EL, van Heuven WJB, Conklin K: The timing and magnitude of Stroop interference and facilitation in monolinguals and bilinguals. Bilingualism: Language and Cognition 2013, 16:420-441.

40. Appelbaum LG, Meyerhoff KL, Woldorff MG: Priming and backward influences in the human brain: processing interactions during the stroop interference effect. Cereb Cortex 2009, 19:2508-2521.

41. Roelofs A: Attention, temporal predictability, and the time course of context effects in naming performance. Acta Psychol (Amst) 2010, 133:146-153.

42. Coderre EL, Conklin K, van Heuven WJB: Electrophysiological measures of conflict detection and resolution in the Stroop task. Brain Res 2011 1413:51-59

43. Glaser WR, Glaser MO: Context effects in stroop-like word and picture processing. J Exp Psychol Gen 1989, 118:13-42.

44. Roelofs A: Goal-referenced selection of verbal action: modeling attentional control in the stroop task. Psychol Rev 2003, 110:88-125.

45. MacLeod CM: Half a century of research on the Stroop effect: an integrative review. Psychol Bull 1991, 109:163-203.

46. Weekes NY, Zaidel E: The effects of procedural variations on lateralized Stroop effects. Brain Cogn 1996, 31:308-330.

47. Liotti M, Woldorff MG, Perez R, Mayberg HS: An ERP study of the temporal course of the Stroop color-word interference effect. Neuropsychologia 2000, 38:701-711.

48. Appelbaum LG, Boehler C, Won R, Davis L, Woldorff MG: Strategic allocation of attention reduces temporally predictable stimulus conflict. J Cogn Neurosci 2012, 24:1834-1848.

49. Bunge SA, Hazeltine E, Scanlon MD, Rosen AC, Gabrieli JDE: Dissociable contributions of prefrontal and parietal cortices to response selection. Neuroimage 2002, 17:1562-1571.

50. Schroeder U, Kuehler A, Haslinger B, Erhard P, Fogel W, Tronnier VM, Lange KW, Boecker H, Ceballos-Baumann AO: Subthalamic nucleus stimulation affects striato-anterior cingulate cortex circuit in a response conflict task: a PET study. Brain 2002, 125:1995-2004.

51. Badre $D$, Wagner AD: Selection, integration, and conflict monitoring: assessing the nature and generality of prefrontal cognitive control mechanisms. Neuron 2004, 41:473-487.

52. Cunnington $R$, Windischberger $C$, Deecke $L$, Moser E: The preparation and readiness for voluntary movement: a high-field event-related fMRI study of the bereitschafts-BOLD response. Neuroimage 2003, 20:404-412

53. Ashburner J: A fast diffeomorphic image registration algorithm Neuroimage 2007, 38:95-113.

54. Calhoun VD, Stevens MC, Pearlson GD, Kiehl KA: fMRI analysis with the general linear model: removal of latency-induced amplitude bias by incorporation of hemodynamic derivative terms. Neuroimage 2004, 22:252-257

55. Brett $M$, Anton JL, Valabregue R, Poline JB: Region of interest analysis using an SPM toolbox, 2002:presented at the 8th international conference on 
functional mapping of the human brain. Sendai, Japan; 2002. Japan. Available on CD-ROM in Neurolmage, Vol 16, No 2. http://marsbar. sourceforge.net/

56. Maldjian J, Laurienti PJ, Kraft RA, Burdette JH: An automated method for neuroanatomic and cytoarchitectonic atlas-based interrogation of fMRI datasets. Neuroimage 2003, 19:1233-1239.

57. Lancaster JL, Rainey LH, Summerlin JL, Freitas CS, Fox PT, Evans AC, Toga AW, Mazziotta JC: Automated labeling of the human brain: a preliminary report on the development and evaluation of a forward-transform method. Hum Brain Mapp 1997, 5:238-242.

58. Lancaster JL, Woldorff MG, Parsons LM, Liotti M, Freitas CS, Rainey L, Kochunov PV, Nickerson D, Mikiten SA, Fox PT: Automated talairach atlas labels for functional brain mapping. Hum Brain Mapp 2000, 10:120-131.

59. Barch DM, Braver TS, Nystrom LE, Forman SD, Noll DC, Cohen JD: Dissociating working memory from task difficulty in human prefrontal cortex. Neuropsychologia 1997, 35:1373-1380.

60. Booth JR, Burman DD, Meyer JR, Gitelman DR, Parrish TB, Mesulam MM: Relation between brain activation and lexical performance. Hum Brain Mapp 2003, 19:155-169.

61. Egner T, Hirsch J: Cognitive control mechanisms resolve conflict through cortical amplification of task-relevant information. Nat Neurosci 2005, 8:1784-1790.

62. Egner T, Hirsch J: The neural correlates and functional integration of cognitive control in a Stroop task. Neuroimage 2005, 24:539-547.

63. Fan J, Fossella J, Sommer T, Wu Y, Posner Ml: Mapping the genetic variation of executive attention onto brain activity. Proc Natl Acad Sci 2003, 100:7406-7411.

64. Rubia K, Smith AB, Brammer MJ, Taylor E: Right inferior prefrontal cortex mediates response inhibition while mesial prefrontal cortex is responsible for error detection. Neuroimage 2003, 20:351-358.

65. Verbruggen F, Aron AR, Stevens MA, Chambers CD: Theta burst stimulation dissociates attention and action updating in human inferior frontal cortex. Neuroimage 2010, 107:13966-13971.

66. Dell'Acqua R, Pesciarelli F, Jolicoeur P, Eimer M, Peressotti F: The interdependence of spatial attention and lexical access as revealed by early asymmetries in occipito-parietal ERP activity. Psychophysiology 2007, 44:436-443.

67. Pulvermüller F, Assadollahi R, Elbert T: Neuromagnetic evidence for early semantic access in word recognition. Eur J Neurosci 2001, 13:201-205.

68. Corbetta M, Patel G, Shulman G: The reorienting system of the human brain: from environment to theory of mind. Neuron 2008, 58:306-324.

69. Small D, Gitelman D, Gregory M, Nobre A, Parrish T, Mesulam M-M: The posterior cingulate and medial prefrontal cortex mediate the anticipatory allocation of spatial attention. Neuroimage 2003, 18:633-641.

70. Braver TS, Paxton JL, Locke HS, Barch DM: Flexible neural mechanisms of cognitive control within human prefrontal cortex. Proc Natl Acad Sci 2009, 106:7351-7356.

71. Braver TS, Gray JR, Burgess GC: Explaining the many varieties of working memory variation: dual mechanisms of cognitive control. In Variations in working memory. Edited by Conway ARA, Jarrold C, Kane MJ, Miyake A, Towse JN. New York, NY: Oxford University Press; 2007:76-106.

72. De Pisapia N, Braver TS: A model of dual control mechanisms through anterior cingulate and prefrontal cortex interactions. Neurocomputing 2006, 69:1322-1326.

\section{Submit your next manuscript to BioMed Central and take full advantage of:}

- Convenient online submission

- Thorough peer review

- No space constraints or color figure charges

- Immediate publication on acceptance

- Inclusion in PubMed, CAS, Scopus and Google Scholar

- Research which is freely available for redistribution

Submit your manuscript at www.biomedcentral.com/submit
Ciomed Central 